\title{
Intraseasonal Variability of Summer Storms over Central Arizona during 1997 and 1999
}

\author{
Pamela L. Heinselman* and David M. Schultz* \\ Cooperative Institute for Mesoscale Meteorological Studies, University of Oklahoma, Norman, Oklahoma
}

(Manuscript received 28 May 2004, in final form 13 July 2005)

\begin{abstract}
Although previous climatologies over central Arizona show a summer diurnal precipitation cycle, on any given day precipitation may differ dramatically from this climatology. The purpose of this study is to investigate the intraseasonal variability of diurnal storm development over Arizona and explore the relationship to the synoptic-scale flow and Phoenix soundings during the 1997 and 1999 North American monsoons. Radar reflectivity mosaics constructed from Phoenix and Flagstaff Weather Surveillance Radar1988 Doppler reflectivity data reveal six repeated storm development patterns or regimes. The diurnal evolution of each regime is illustrated by computing frequency maps of $25 \mathrm{dBZ}$ and greater reflectivity during 3-h periods. These regimes are named to reflect their regional and temporal characteristics: dry regime, eastern mountain regime, central-eastern mountain regime, central-eastern mountain and Sonoranisolated regime, central-eastern mountain and Sonoran regime, and nondiurnal regime. Composites constructed from the NCEP-NCAR 40-Year Reanalysis Project data show that regime occurrence is related to the north-south location of the 500-hPa geopotential height ridge axis of the Bermuda high and the east-west location of the 500-hPa monsoon boundary, a boundary between dry air to the west and moist air to the east. Consequently, precipitable water from the 1200 UTC Phoenix soundings is the best parameter for discriminating the six regimes.
\end{abstract}

\section{Introduction}

Over $63 \%$ of Arizona's 5.13 million residents live in Phoenix-Mesa, a metropolitan area with an explosive population growth of $45.3 \%$ between 1990 and 2000 (http://www.census.gov/prod/2001pubs/c2kbr01-2. pdf). With this rapidly growing population, potential impacts from summertime convective storms are increasing. Socioeconomic impacts from storms can include damage to property and threat to life from high winds, flash flooding, and/or lightning (Sellers and Hill 1974; Hales 1975; Schmidli 1986). Additionally, downed power lines from high winds can result in loss of profits to power companies, disruption to life and businesses, and transportation delays. Although summer storms are sometimes hazardous, farmers and cattle ranchers depend on storm runoff to keep their vegetation thriv-

\footnotetext{
* Additional affiliation: NOAA/National Severe Storms Laboratory, Norman, Oklahoma.
}

Corresponding author address: Dr. Pamela L. Heinselman, NSSL, 1313 Halley Circle, Norman, OK 73069.

E-mail: pam.heinselman@noaa.gov ing (Jurwitz 1953; Sellers and Hill 1974). Because Arizona receives up to $50 \%$ of its annual rainfall from summer storms, improved understanding of the intraseasonal variability of storm development and the associated environmental conditions are important to public safety and economics.

Arizona's summer wet season occurs in response to the North American monsoon (NAM), a reversal in circulation at low and midlevels over Mexico and the Desert Southwest every July and August (e.g., Douglas et al. 1993; Adams and Comrie 1997).

At low levels, a thermal low forms over the Colorado Plateau (Tang and Reiter 1984; Rowson and Colucci 1992; Mohr 2004), modulating the low-level transport of moisture (Kanamitsu and Mo 2003) from the eastern Pacific, Gulf of California, and Gulf of Mexico (e.g., Hales 1972b, 1974; Brenner 1974; Douglas et al. 1993; Douglas 1995; Schmitz and Mullen 1996; Stensrud et al. 1997; Berbery and Fox-Rabinovitz 2003). Moisture from the Gulf of California is transported into Arizona by a daily low-level jet (Douglas 1995) and occasional surges from the Gulf of California (e.g., Hales 1972b, 1974; Brenner 1974; Stensrud et al. 1997; Douglas and Leal 2003; Higgins et al. 2004). Anderson et al. (2004) show that once precipitation begins, the recycling of 


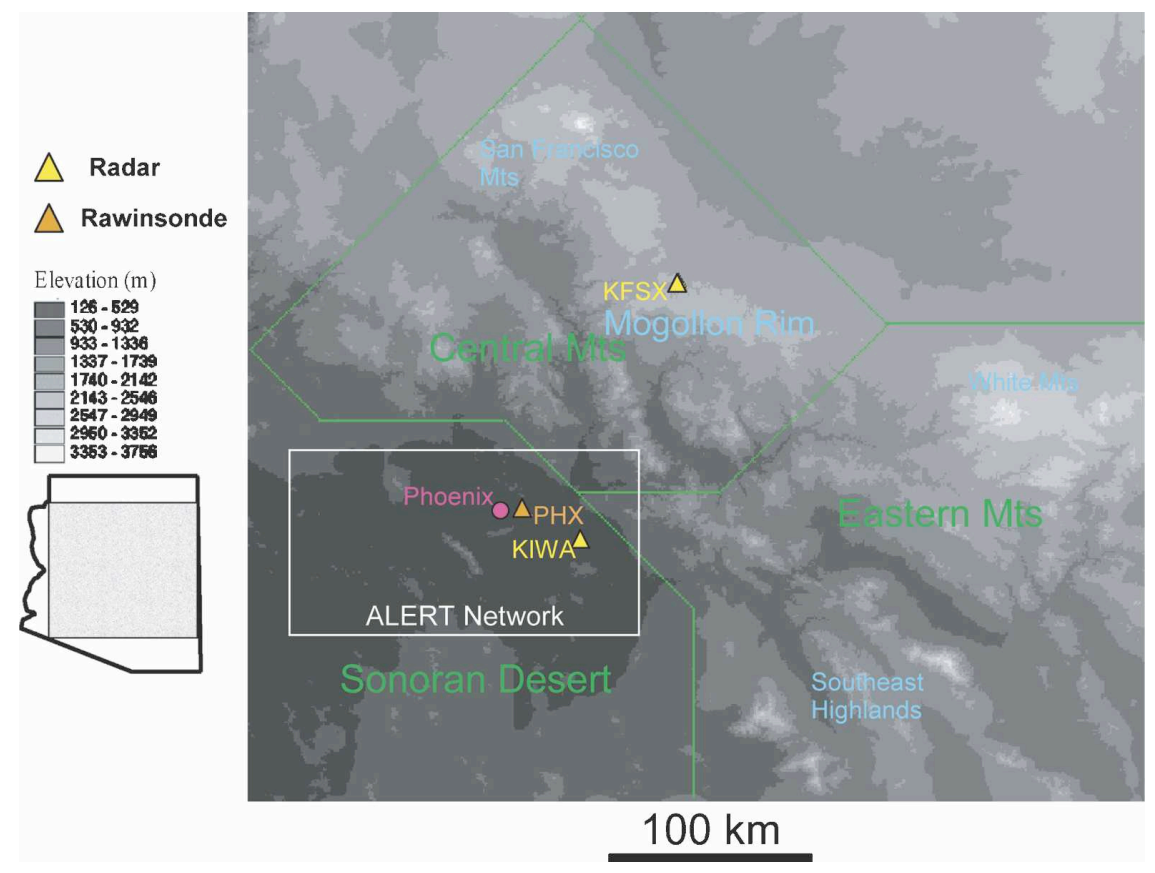

FIG. 1. Elevation $(\mathrm{m})$ of terrain features in the domain, gridded at 1-km resolution from 30 arcsecond U.S. Geological Survey data. Also shown are the locations of the WSR-88D sites (yellow triangles), the Phoenix rawinsonde site (orange triangle), Phoenix (pink circle), the three primary regions (green letters), and significant mountain ranges within the domain (light blue). The white box denotes the regional extent of the ALERT network of rain gauges used in this study.

moisture from evaporation is also important for supporting regional precipitation. The northward and westward expansion of the Bermuda high [hereafter, subtropical high; e.g., Bryson and Lowry (1955), Douglas et al. (1993), Adams and Comrie (1997), and Barlow et al. (1998)] allows the transport of midlevel moisture from the Gulf of Mexico (Schmitz and Mullen 1996) and mesoscale convective systems that form over the Sierra Madre (Berbery 2001; Anderson et al. 2004). This low-midlevel transport of moisture over Arizona, an otherwise arid environment, contributes to a largescale environment supportive of convective storm development.

Because of Arizona's mountainous terrain (Fig. 1), the precipitation climatology exhibits a diurnal cycle. In the morning, storms tend to initiate over the Mogollon Rim, White Mountains, and southeast highlands. During the afternoon, storms tend to move southward along the Mogollon Rim and southwestward from the White Mountains and southeast highlands, culminating in the Sonoran Desert near sundown. This evolution is ubiquitous: it appears in diurnal climatologies using precipitation gauge (Balling and Brazel 1987), lightning (Watson et al. 1994a; King and Balling 1994), and radar reflectivity data (Hales 1972a; MacKeen and
Zhang 2000). Despite this robust diurnal precipitation cycle, tremendous intraseasonal variations in the occurrence, timing, and location of convective storms are possible.

Historically, intraseasonal variations in Arizona's precipitation during the NAM are categorized as wet and dry periods, or bursts and breaks, respectively (Carleton 1986; Watson et al. 1994b; Mullen et al. 1998). Burst and break studies investigate differences between composited synoptic-scale patterns to help forecasters discern environments supporting or inhibiting precipitation and have employed three different datasets: 1980-82 Geostationary Operational Environmental Satellite-West (GOES-West) infrared satellite data over the southwest United States (Carleton 1986), 1985-1990 Bureau of Land Management cloud-to-ground lightning data over Arizona (Watson et al. 1994b), and 1985-92 precipitation data over southeastern Arizona (Mullen et al. 1998). Cavazos et al. (2002) present a more modern approach toward bursts and breaks where several wet and dry monsoon modes are identified by applying a neural network-based classification technique to various atmospheric fields during JuneSeptember 1980-93.

Burst and break studies have investigated the role 
and origin of low-level versus midlevel moisture in bursts and breaks. During the 1981-83 NAMs, Carleton (1986) found the surface circulation is essentially the same during wet and dry periods: a thermal low resides over Arizona. Furthermore, Mullen et al. (1998) show that similar amounts of moisture are transported at low levels from the northern Gulf of California into southern Arizona during both bursts and breaks. This result was confirmed by Berbery (2001), who found a large divergence of moisture flux over the northern Gulf of California throughout three NAM seasons, and was supported by previous analyses showing positive water vapor flux at low levels from the northern Gulf of California into Arizona during the summer (Rasmusson 1967; Houghton 1979; Tang and Reiter 1984; BadanDangon et al. 1991; Douglas 1995; Schmitz and Mullen 1996; Higgins et al. 1997). In contrast, the midlevel circulation differs significantly during bursts and breaks, such that the 500 -hPa subtropical high ridge axis is located farther north during bursts than breaks (Carleton 1985, 1986; Watson et al. 1994b; Mullen et al. 1998; Cavazos et al. 2002). Most importantly, more moisture is transported at midlevels into southeastern Arizona from the Gulf of Mexico during bursts than breaks (Mullen et al. 1998).

A question is whether this binary stratification of intraseasonal variability (i.e., bursts and breaks) and synoptic-scale flow provides useful guidance for forecasts of regional precipitation on individual days. A better understanding of the intraseasonal variability of storm development during the NAM may lead to improved regional forecasts of storm likelihood that may, in turn, help residents and businesses prepare better for possible threats to life, damage to property, and loss of profit.

Since 1997, the availability of Weather Surveillance Radar-1988 Doppler (WSR-88D) radar data in Arizona at Phoenix and Flagstaff has afforded an opportunity to investigate intraseasonal variability at higher temporal and spatial resolution than lightning- (Watson et al. 1994b; Wallace 1997; Wallace et al. 1999), satellite(Carleton 1986), and precipitation-gauge-based studies (Mullen et al. 1998). This paper uses these radar data to investigate the scope of intraseasonal variability of storms over central Arizona during July and August 1997 (an average NAM) and 1999 (a particularly wet NAM). By using WSR-88D radar reflectivity data, the investigation of daily storm development is based on temporal and spatial resolutions more similar to those faced by forecasters. As described in section 2 and the appendix, radar reflectivity data from both the Phoenix and Flagstaff WSR-88Ds are combined to produce a mosaic of reflectivity fields with spatial continuity over mountainous terrain between these sites. Section 3 describes regional, temporal, and directional characteristics of six storm development patterns classified manually during the 1997 and 1999 NAMs. These findings are validated by quantifying regional and temporal characteristics of storm development. Additionally, composite 500-hPa maps, constructed from the National Centers for Environmental Prediction-National Center for Atmospheric Research (NCEP-NCAR) 40Year Reanalysis Project data (Kalnay et al. 1996), are used to describe mean characteristics of the synopticscale midlevel flow and moisture fields related to each pattern. In section 4, composite Phoenix soundings are found for each of the six regimes to validate the essential features of the composite $500-\mathrm{hPa}$ maps and describe the mean vertical structure of the environment. The summary and conceptual model tying these results together are presented in section 5.

\section{Radar data and 500-hPa composites}

This section describes the data and methodology used to study the variety of diurnal storm development regimes over central Arizona. Diurnal storm development is defined as both the initiation and subsequent evolution of storms occurring each day. First, we present the radar data and objective analysis techniques used to construct high-resolution reflectivity mosaics. Second, we show how these reflectivity mosaics are used to assess the intraseasonal variability of storm development during the NAM. Third, we describe the construction of $500-\mathrm{hPa}$ composites from NCEPNCAR reanalysis data (Kalnay et al. 1996).

Intraseasonal variability in storm development is investigated using WSR-88D level II radar reflectivity data from the Phoenix (KIWA) and Flagstaff (KFSX) sites (Fig. 1) during two NAM seasons, July and August 1997 and 1999, respectively. The choice of these periods arose from three considerations. First, the analysis period begins in 1997 because it marks the first year where radar data are available from both the Phoenix and Flagstaff WSR-88D sites. Second, as this study is also concerned with the associated variability of the tropospheric environment at Phoenix, the 1998 summer season is excluded because of large gaps in the archived sounding data. Third, analyses span July-August because precipitation associated with the NAM usually begins in early July, and dissipates during September (Sellers and Hill 1974). During these periods, 24-h WSR-88D data are available for 107 of the 124 days (86\% of events), with 14 days (3 days) missing from the 1997 (1999) dataset. Because this study examines two NAMs only, the true extent of the intraseasonal variety 
TABLE 1. Distribution of reflectivity regimes during the 1997 and 1999 NAMs for the dry regime (DR), eastern mountain regime (EMR), central-eastern mountain regime (CEMR), central-eastern mountain and Sonoran Desert regime (CEMSR), nondiurnal regime (NDR), and unclassified regime (UNC), where MISS is days missing from the radar dataset. Entries in boldface highlight the two regime types that occur most frequently in 1997 and 1999.

\begin{tabular}{|c|c|c|c|c|c|c|c|c|}
\hline & DR & EMR & CEMR & CEMSIR & CEMSR & NDR & UNC & MISS \\
\hline Jul-Aug 1997 & $8(13 \%)$ & $4(6 \%)$ & $2(3 \%)$ & $6(10 \%)$ & $11(18 \%)$ & $10(16 \%)$ & $7(11 \%)$ & $14(23 \%)$ \\
\hline Jul-Aug 1999 & $4(6 \%)$ & $5(8 \%)$ & $6(10 \%)$ & $3(5 \%)$ & $19(31 \%)$ & $20(32 \%)$ & $2(3 \%)$ & $3(5 \%)$ \\
\hline Tot & $12(9.5 \%)$ & $9(7 \%)$ & $8(6.5 \%)$ & $9(7 \%)$ & $30(24 \%)$ & $30(24 \%)$ & $9(7 \%)$ & $17(14 \%)$ \\
\hline
\end{tabular}

of diurnal storm development patterns may not be captured. Nevertheless, this study provides the first examination of these patterns using high-resolution radar reflectivity data.

Radar data from KIWA and KFSX are quality controlled to minimize echo from nonmeteorological sources, as detailed in the appendix. Data from these two radars are then combined to produce a single product termed the composite mosaic grid, aimed at minimizing radar data limitations and providing a more complete depiction of precipitation than either radar alone (Zhang et al. 2005). Composite mosaics are a two-dimensional field of maximum reflectivity values within each column of reflectivity data $(1 \mathrm{~km} \times$ $1 \mathrm{~km} \times 12 \mathrm{~km})$ and are created every $10 \mathrm{~min}$. The details of the mosaic process are discussed in the appendix.

The variety of diurnal storm development patterns that evolve during 1997 and 1999 is investigated by examining manually the spatial and temporal characteristics of diurnal storm development (a day is defined as the 24-h period beginning at 1200 UTC) over three regions of central Arizona: eastern mountains, central mountains, and Sonoran Desert (Fig. 1). To expedite this process, hourly frequencies of composite mosaics of reflectivity $25 \mathrm{dBZ}$ and higher are calculated beginning at the top of each hour. The $25-\mathrm{dBZ}$ threshold serves as a proxy for storm occurrence. Next, hourly frequencies of reflectivity $25 \mathrm{dBZ}$ and higher are displayed on a high-resolution terrain map $(1 \mathrm{~km} \times 1 \mathrm{~km}$ spacing), animated, and analyzed manually to assess the defining spatial and temporal characteristics of diurnal storm occurrence. Defining characteristics are designed to reflect forecast concerns: the timing and location of storm initiation (i.e., first occurrence of nonzero frequencies and their spatial extent), locations of subsequent storm development, and the timing and location of storm demise (i.e., the last occurrence of nonzero frequencies and their spatial extent). This manual assessment provided an in-depth knowledge of each day's initial and subsequent storm evolution unattainable by automated techniques.

During our examination of the 107 days, it became clear to us that there were distinct and repeated patterns among the defining characteristics during the 1997 and 1999 NAMs. For example, on some days, initial storm occurrence was tied to mountainous terrain in eastern Arizona with subsequent storm occurrence limited to the eastern third of the domain. On other days, initial and subsequent storm occurrences extended across the entire Mogollon Rim. Still, on some days, initial storm occurrence not only extended across the Mogollon Rim, but subsequently progressed toward lower elevations over the Sonoran Desert. These differences in the defining characteristics of diurnal storm occurrence form the basis of our classification. The grouping of days with similar defining characteristics reveals six repeated diurnal storm occurrence regimes (Table 1 and Fig. 2). Inherently, there are discrepancies in the details among days with similar defining characteristics. Nevertheless, most events $(\sim 80 \%)$ fit easily into one of the six regimes with little ambiguity, implying some robustness to this classification. As shown in the next section, differences in the defining characteristics of the six regimes are illustrated by computing diurnal 3-h frequencies (e.g., 1200-1400, 1500-1700, 1800-2000 UTC; LST $=$ UTC $-7 \mathrm{~h}$ ) of composite radar reflectivity, $25 \mathrm{dBZ}$ and higher, from the 10-min mosaics for days composing each regime.

To understand the synoptic-scale factors that relate to the evolution of the six regimes, we examine composite 1200 UTC 500-hPa maps of geopotential height and specific humidity prior to the development of each regime. We choose $500 \mathrm{hPa}$ because the previous literature shows that midlevel flow is important to the occurrence of bursts and breaks (Carleton 1986; Watson et al. 1994b; Mullen et al. 1998; Cavazos et al. 2002). These composites are constructed from NCEP-NCAR reanalysis data [Kalnay et al. 1996; available online at the National Oceanic and Atmospheric Administration-Cooperative Institute for Research in Environmental Sciences (NOAA-CIRES) Climate Diagnostic Center's Web site http://www.cdc.noaa.gov]. Characteristics of the six regimes and their related composite 1200 UTC 500-hPa flow are described in the next section. 

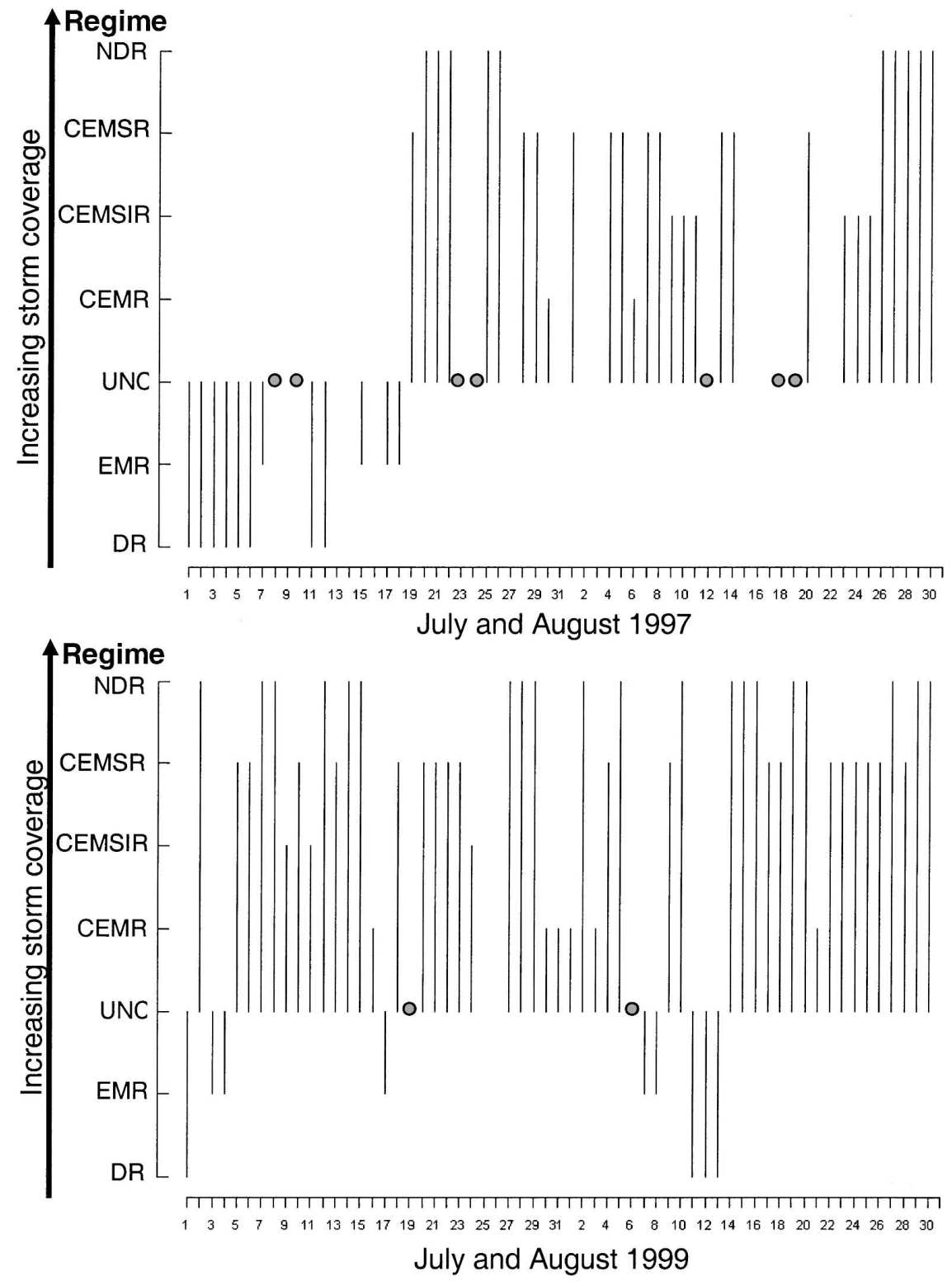

FIG. 2. Temporal distribution of the regimes during the 1997 and 1999 NAMs. Dry days are denoted by open circles and days lacking radar data are left blank.

\section{Radar reflectivity regimes and $500-\mathrm{hPa}$ synoptic-scale flow}

Six repeated storm development regimes are found over the domain (Table 1 and Fig. 2). Figure 2 shows the temporal evolution of these regimes during the 1997 and 1999 NAMs. Based on the defining characteristics, relative frequencies of composite reflectivity evolve with similar spatial and temporal characteristics in five of the six regimes. The naming of these regimes reflects the regional extent of storm coverage and includes 1) dry regime (DR; 12 days or $9.5 \%$ of 124 events), 2) eastern mountain regime (EMR; 9 days or $7 \%$ of events), 3) central-eastern mountain regime (CEMR; 8 days or $6.5 \%$ of events), 4) central-eastern mountain and Sonoran-isolated regime (CEMSIR; 9 days or 7\% of events), and 5) central-eastern mountain and Sonoran regime (CEMSR; 30 days or $24 \%$ of events). The sixth regime is distinguished by storm development that is less closely tied to the climatological diurnal cycle, and therefore is called the nondiurnal regime (NDR; 30 days or $24 \%$ of events). Nine days or $7 \%$ of events feature storms that occur over various isolated areas in central Arizona (called unclassified), and 17 days or 
$14 \%$ the radar dataset are missing. Both unclassified and missing events are excluded hereafter, such that 107 of 124 possible events are examined.

Below, each regime's diurnal storm evolution is illustrated by 3 -h frequencies of composite radar reflectivity during the period of peak storm development (i.e., 1800-0900 UTC).

\section{a. Dry regime}

The DR is indicated by an absence of radar reflectivity or rainfall across the domain and occurs $9.5 \%$ of the time, with higher frequency during 1997 than 1999 (13\% versus $6 \%$, respectively). The higher frequency of DR in 1997 results from several consecutive dry days during early July (Fig. 2). The relatively low number of dry days each year indicates that once more active regimes arise, ingredients necessary for storm development (Johns and Doswell 1992) are rarely absent over the domain. During the DR, 500-hPa flow is dominated by a low-amplitude ridge and relatively dry air, especially over southern California, Nevada, and Arizona (Fig. 3a). As a result, the 500 -hPa flow over Arizona is westerly and the latitude of the subtropical high's horizontal ridge axis $\left(30^{\circ} \mathrm{N}\right)$ is farther south during $\mathrm{DR}$ than the rest of the NAM season (Fig. 3a). This pattern is similar to break composites by Carleton $(1985,1986)$, Watson et al. (1994b), and Mullen et al. (1998). The DR composite is also similar to Cavazos et al.'s (2002) first monsoon mode, which depicts premonsoon conditions.

\section{b. $E M R$}

EMR is characterized predominantly by storm development over the mountains of eastern Arizona (Fig. 4). Storms develop first in the vicinity of the White Mountains and the southeast highlands in the early afternoon (1800-2000 UTC; Fig. 4a). By midafternoon, the areal extent of storm development is maximized, as storms begin to move toward lower elevations (2200-0000 UTC; Fig. 4b). Toward evening, storm development is most frequent over the southeast highlands (0200-0400 UTC; Fig. 4c), and, by early morning, storm development begins to diminish (0600-0800 UTC; Fig. 4d). Compared with the other regimes, EMR evolves over the smallest geographic region and its frequencies of radar reflectivity are comparatively low. These lower frequencies result, in part, from radar beam blockage over the southeast highlands and may indicate high spatial and temporal variability in storm development within a relatively small sample size.

During EMR, regional storm development occurs within a confluence zone that marks the transition in flow between the drier air associated with a trough over

\section{(a) DR}

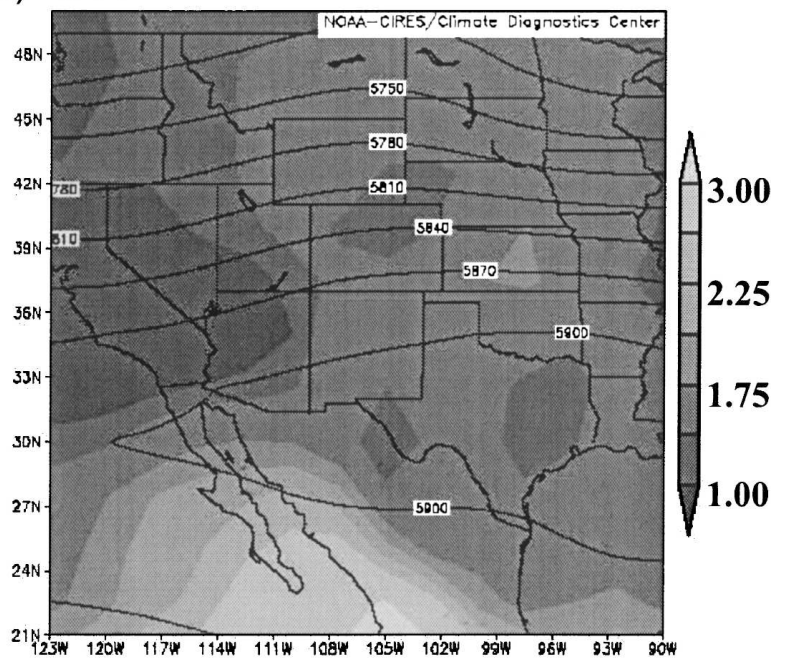

(b) EMR

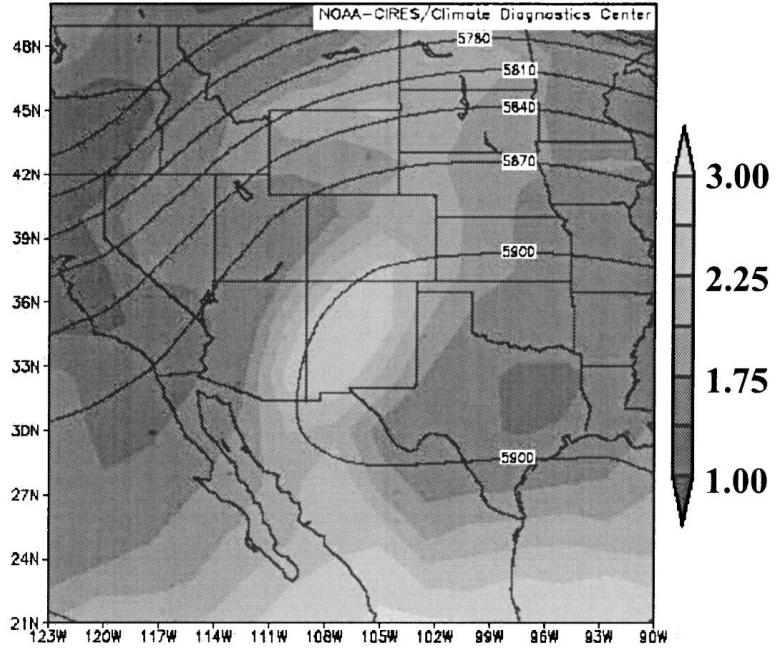

FIG. 3. Composite 500-hPa map of geopotential height (m) overlaid on a shaded specific humidity field $\left(\mathrm{g} \mathrm{kg}^{-1}\right)$ for (a) DR $(N=12)$ and (b) EMR $(N=9)$, where $N$ is the number of days. Image is provided by the NOAA-CIRES Climate Diagnostics Center, Boulder, CO, from their Web site (http://www.cdc.noaa. gov).

the North Pacific Ocean and the more moist air of the subtropical high (Fig. 3b). Adang and Gall (1989) call this transition zone the monsoon boundary and show that it extends vertically from the surface to $400 \mathrm{hPa}$. They also diagnose a direct ageostrophic circulation driven by frontogenetic forcing, with rising (descending) air east (west) of the boundary (Fig. 9 of Adang and Gall 1989). Because the monsoon boundary is positioned between central and far eastern Arizona during EMR (Fig. 3b), we surmise that regional storm occurrence is supported on the moist (east) side of the boundary, where both orographic and frontogenetic 


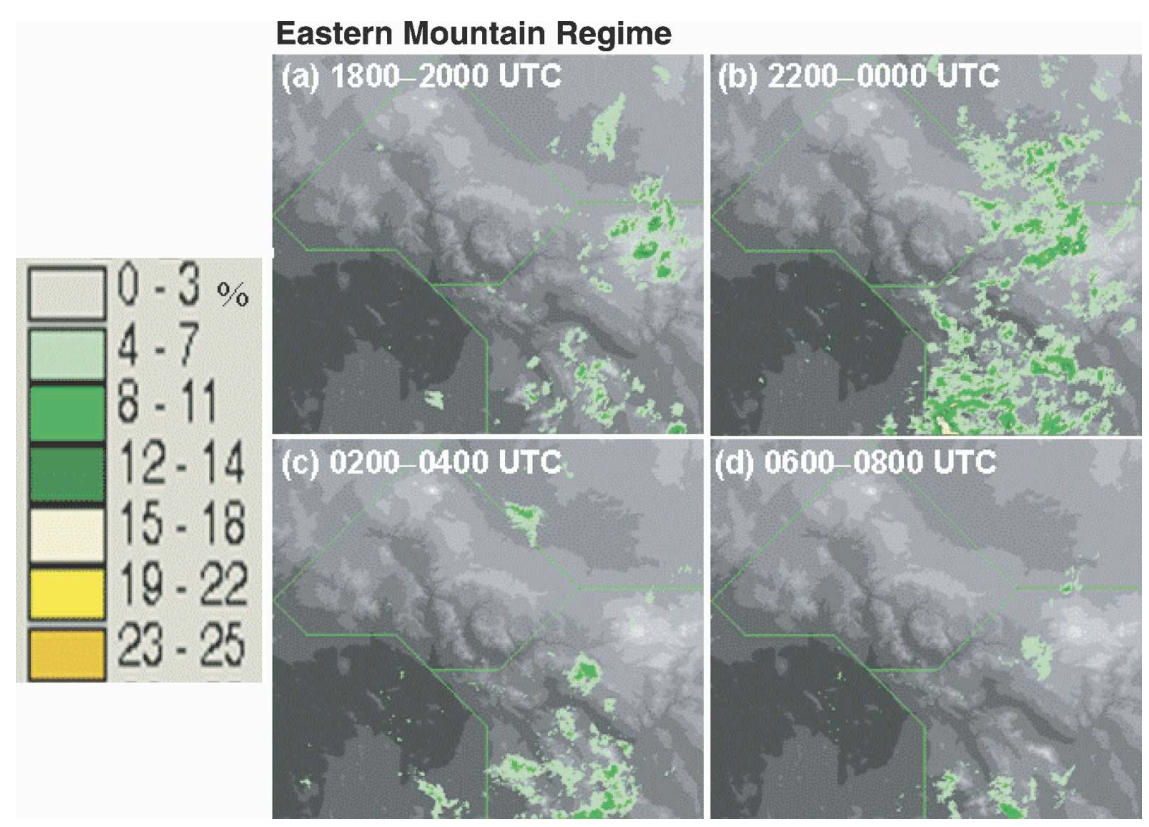

FIG. 4. Frequency of composite radar reflectivity $25 \mathrm{db} Z$ and higher during the EMR $(N=$ 9) from (a) 1800-2000, (b) 2200-0000, (c) 0200-0400, and (d) 0600-0800 UTC.

forcing of warm, moist air are possible. The EMR composite is most similar to Cavazos et al.'s (2002) 11th monsoon mode, which occurs during July-September.

\section{c. $C E M R$}

CEMR is characterized predominantly by storm development over the central mountains, accompanied by storm development over the White Mountains and southeast highlands (Fig. 5). Storms develop first over the higher elevations of the Mogollon Rim and peaks of the White Mountains (1800-2000 UTC; Fig. 5a). Like EMR, by midafternoon, the areal extent of storm development is maximized as storms begin to move toward lower elevations (2200-0000 UTC; Fig. 5b). Toward evening, the areal extent of storm development over the Mogollon Rim is greatly diminished (0200-

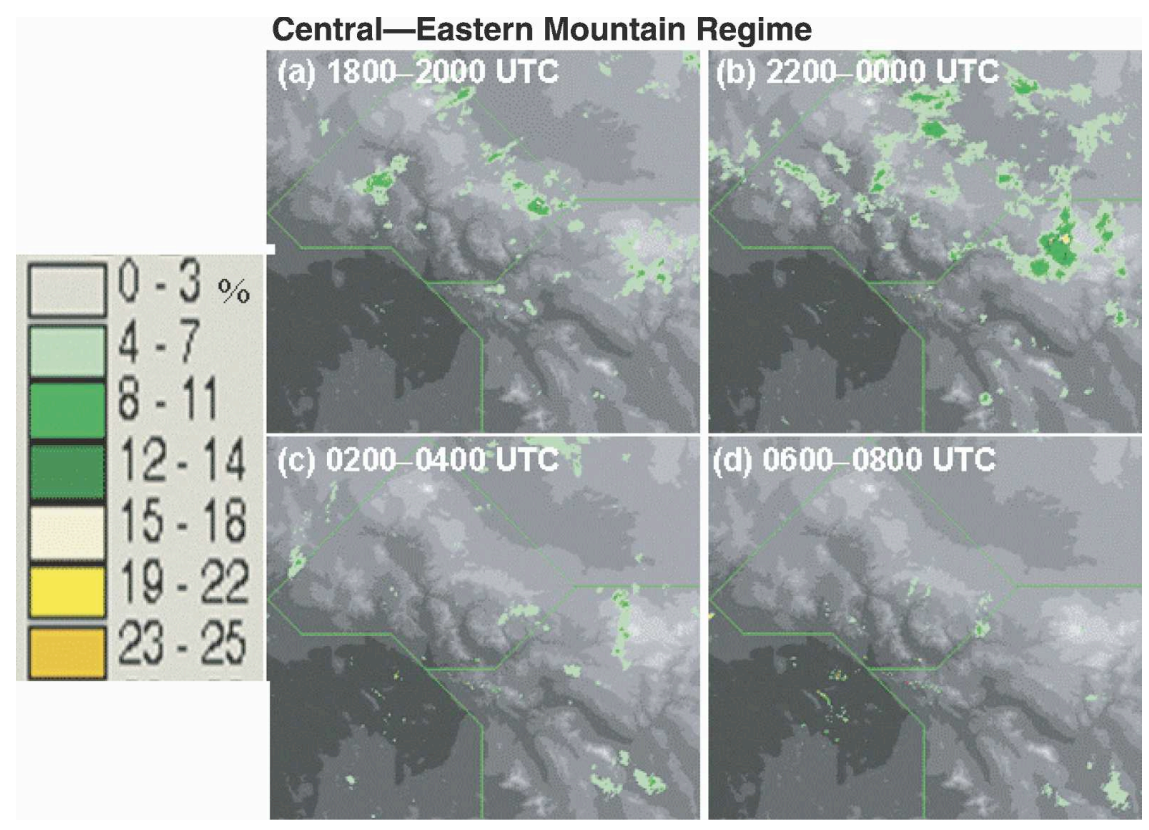

FIG. 5. Same as in Fig. 4, but during CEMR $(N=8)$. 
0400 UTC; Fig. 5c) and by early morning, storm development is infrequent (0600-0800 UTC; Fig. 5d). The major difference between CEMR and EMR is the expanded storm development across the Mogollon Rim (cf. Figs. 4 and 5). This expanded storm development is associated with a northwestward shift in geopotential height that corresponds with a broadening of the meridional axis of moist air over northern Arizona and into the west-central United States (Fig. 7a). The similarity of this synoptic-scale pattern to that of EMR suggests the same processes as in EMR, only shifted northwestward and expanded in scale (cf. Figs. 3b and 7a). The CEMR composite is similar to modes 13 and 14 of Cavazos et al. (2002), which usually occur in July and August.

\section{d. CEMSIR}

CEMSIR is characterized by storm development over all three regions. On these days, early afternoon storm development over higher elevations of the San Francisco Mountains, Mogollon Rim, White Mountains, and southeast highlands is accompanied by isolated storm development over the Sonoran Desert (1800-2000 UTC; Fig. 6a). This early afternoon storm development is more widespread over mountainous terrain compared with CEMR and EMR. Along the Mogollon Rim, there is a tendency also for higher frequencies of radar reflectivity during CEMSIR than CEMR (19\%-22\% versus $8 \%-11 \%$, respectively; cf. Figs. $6 a$ and $5 a)$. By midafternoon this region of frequencies expands to the north and south and its magnitude intensifies along the northern ranges of the Mogollon Rim (2000-0000 UTC; Fig. 6b). Compared with CEMR, this band of high frequencies is more distinct and intense (maximum frequencies $23 \%-25 \%$; cf. Figs. $5 \mathrm{~b}$ and $6 \mathrm{~b}$ ) and reflects the tendency for more organized storm development during CEMSIR. Toward evening (0200-0400 UTC), storm occurrence is more abundant over the central mountains, southeast highlands, and the Sonoran Desert than during EMR and CEMR (cf. Figs. 4c, 5c, and 6c). By early morning, storm development remains active mostly over the Mogollon Rim and southeast highlands (0600-0800 UTC; Fig. 6d). The primary differences between CEMSIR and CEMR are more frequent and widespread storm development across the Mogollon Rim, White

FIG. 6. Same as in Fig. 3, but for (a) CEMR $(N=8)$, (b) CEMSIR $(N=9)$, and (c) CEMSR $(N=30)$. Image is provided by the NOAA-CIRES Climate Diagnostics Center, Boulder, CO, from their Web site (http://www.cdc.noaa.gov).

\section{(a) CEMR}

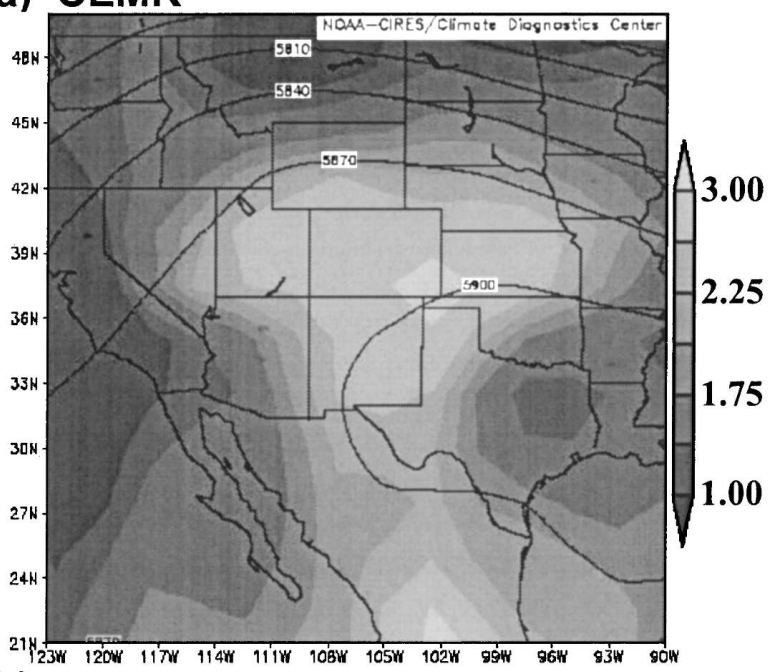

(b) CEMSIR

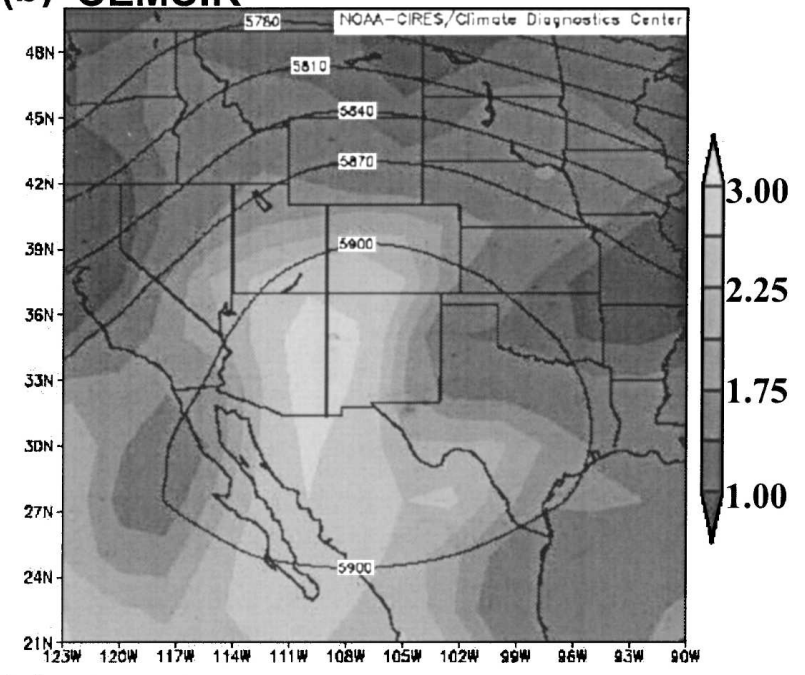

(c) CEMSR

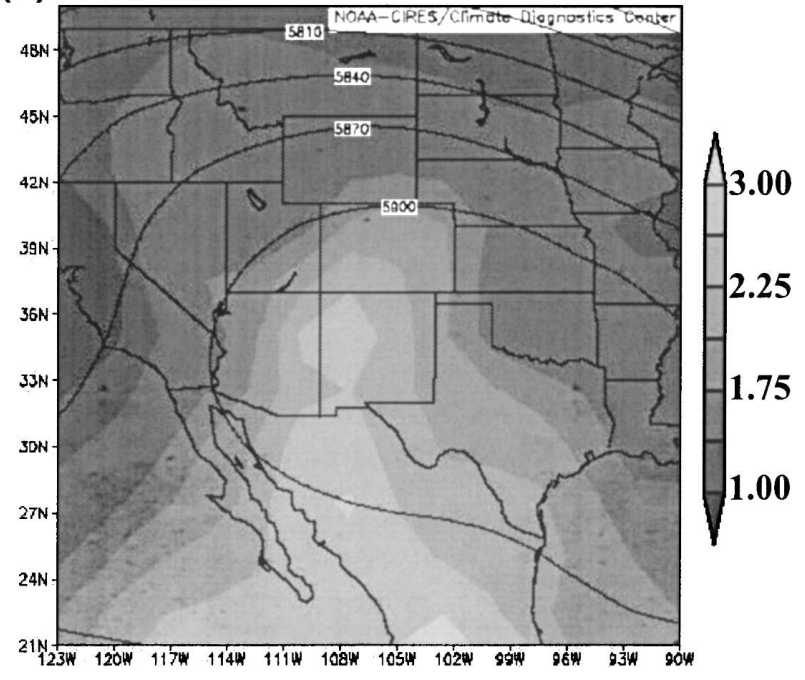




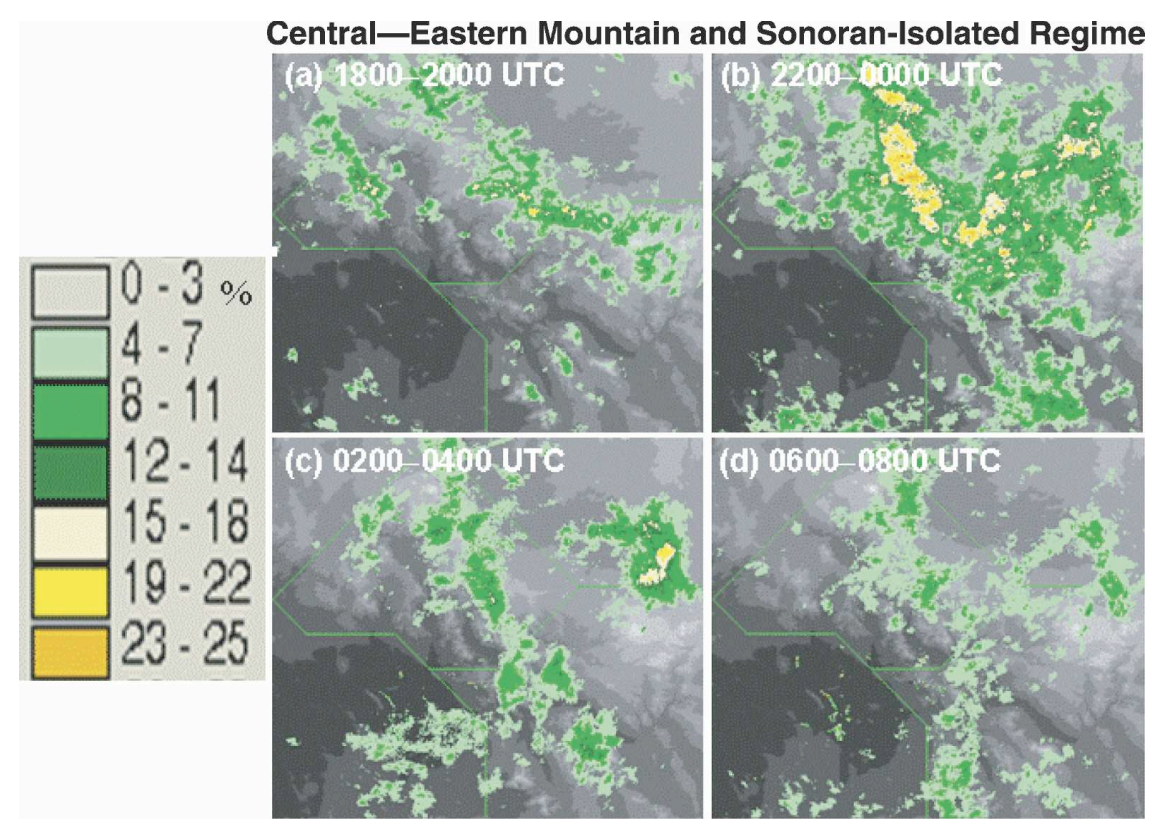

FIG. 7. Same as in Fig. 4 , but during CEMSIR $(N=9)$.

Mountains, and southeast highlands, and isolated storm occurrence over the Sonoran Desert.

During CEMSIR, the composite 500-hPa flow is anticyclonic over north-central Mexico, eastern Arizona, New Mexico, and the Texas Panhandle, with a meridional axis of moist air (maximum specific humidity $\geq 3$ $\mathrm{g} \mathrm{kg}^{-1}$ ) centered over the border of Arizona and New Mexico (Fig. 7b). This synoptic-scale flow differs from that of CEMR in that the ridge is more amplified and its vertical ridge axis is shifted farther west, creating a flow with a stronger southerly component (cf. Figs. 7a and $7 \mathrm{~b}$ ). In addition, the meridional moisture axis is shifted westward into Arizona (cf. Figs. 7a and 7b), providing a midlevel environment more favorable for storm development over the Sonoran Desert.

\section{e. CEMSR}

CEMSR is characterized by storm development initially over the Mogollon Rim, southeast highlands, and central mountains, and later over the Sonoran Desert (Fig. 8). During the early afternoon, storms develop over higher elevations of the San Francisco Mountains, Mogollon Rim, White Mountains, and southeast highlands (1800-2000 UTC; Fig. 8a). This early afternoon storm development is similar to that of CEMSIR (cf. Figs. 6a and 8a). By midafternoon this region of frequencies expands to the north and south, and its magnitude intensifies along the southern ranges of the Mogollon Rim (2000-0000 UTC; Fig. 8b). The southward displacement of this band of high frequencies, com- pared with CEMSIR, indicates more storm movement to lower elevations (cf. Figs. $6 \mathrm{~b}$ and $8 \mathrm{~b}$ ). Over the southern Sonoran Desert, storms occur because of both the isolated development over the Sonoran Desert and more organized storm movement from the southeast highlands into the lower desert (Fig. 8b). Toward evening, storm development is most widespread over the Sonoran Desert, with a frequency of composite reflectivity maxima over the southwest and southeast parts of the desert (0200-0400 UTC; Fig. 8c). By early morning, storm development is diminished over the central mountains but remains somewhat active over the southeast highlands and the Sonoran Desert (Fig. 8d). The storm evolution of this regime is similar to that depicted by Arizona's diurnal climatology, capturing both the afternoon precipitation maxima over mountainous terrain and the late night precipitation maxima over the Sonoran Desert (Balling and Brazel 1987; King and Balling 1994; Watson et al. 1994a). As four of the six (52\% of days) regimes involve storm development over mountainous terrain during the afternoon, the similarity between the EMR, CEMR, CEMSIR, CEMSR, and climatology is hardly surprising.

During CEMSR, the $500-\mathrm{hPa}$ anticyclonic flow is broader than that during CEMSIR and tilted toward the northwest, with a meridional axis of moist air centered over the border of Arizona and New Mexico (Fig. 7c). Although this pattern is similar to that of CEMSIR, the ridge is shifted slightly northward and its axis is tilted toward the northwest, creating a flow with a 


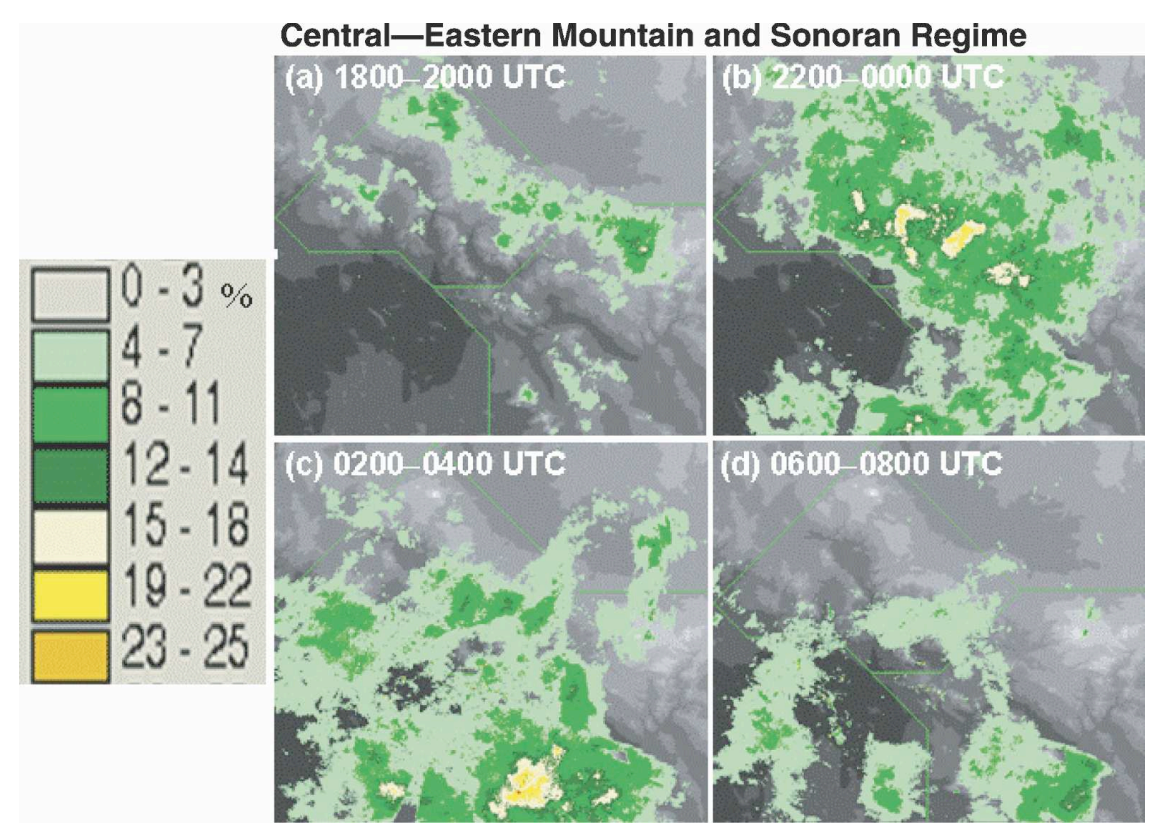

FIG. 8. Same as in Fig. 3, but during CEMSR $(N=30)$.

stronger easterly component (cf. Figs. 7b and 7c). Furthermore, although storm development is more widespread over the Sonoran Desert during CEMSR than CEMSIR, the midlevel environment is less moist (cf. Figs. 7b and 7c). The CEMSR composite is most similar to mode 10 of Cavazos et al. (2002), which usually occurs in July and August.

\section{f. $N D R$}

NDR is characterized by storm development that is tied less strongly to the topographically influenced diurnal precipitation cycle than the previous four regimes (EMR, CEMR, CEMSIR, and CEMSR; cf. Figs. 3, 5, 6, 8 , and 9). Lower frequencies of reflectivity illustrate the relative lack of common storm evolution during these events. Regardless of these differences, like CEMSR, during the afternoon and evening storm development is widespread over all three regions (cf. Figs. 8b,c and $9 b, c)$. Although NDR's diurnal cycle of reflectivity frequency shows regional storm development that is somewhat similar to CEMSR, on a given day, storm development can differ markedly from that shown in Fig. 9. Oftentimes, storm development is organized in linear convective lines (Smith and Gall 1989) or evolves into a mesoscale convective system (McCollum et al. 1995). Furthermore, storms may be oriented perpendicular, rather than parallel, to terrain features, and move northerly, easterly, or westerly.

Because storm systems may move eastward, northward, or westward during NDR, a 500-hPa composite is constructed for each storm movement direction (Fig. 10). A comparison of these composites reveals that, within each pattern, the monsoon boundary is located over far western Arizona, with a meridional moisture axis that is centered over central Arizona and extends northeastward into Colorado. The westward shift in the moisture axis in NDR, relative to the other regimes, results in the increased availability of midlevel moisture across the entire domain, including the Sonoran Desert. Although the moisture field is similar among the three NDR types, characteristics of their geopotential height composites differ.

NDR days with eastward storm movement exhibit the most unique 500-hPa flow: a short-wave trough in the westerlies just west of Arizona, and a subtropical high centered over Oklahoma and Texas (Fig. 10a). This pattern is similar to both the $500-\mathrm{hPa}$ composite found by Carleton (1986) and to the 15th mode found by Cavazos et al. (2002). In this case, the flow is indicative of synoptic-scale forcing ahead of the short-wave trough, which, in turn, may enhance lift in a region where orographic forcing is prevalent and deep moisture is abundant (shown later). In addition, the southwesterly steering-level flow, and anticipated northeastward track of the short-wave trough, are likely responsible for the observed eastward storm movement.

On days where storms move northward, the North Pacific trough and large-scale ridge are shifted westward, relative to the eastward-moving storm composite (cf. Figs. 10a and 10c). This 500-hPa flow is comparable 




FIG. 9. Same as in Fig. 4, but during NDR $(N=30)$.

to CEMR (and modes 13 and 14 of Cavazos et al. 2002), except that the meridional moisture axis is shifted westward and extends farther northward (cf. Figs. 7a and 10b). This synoptic-scale pattern provides southerly flow over Arizona, which favors northward-moving storms.

During NDR days with westward storm movement, the large-scale flow is similar to that on northwardmoving days (and mode 10 of Cavazos et al. 2002), except that the horizontal ridge axis is tilted toward the northwest, creating southeasterly flow favorable for westward storm movement (cf. Figs. 10b and 10c). Although the composite 500-hPa flows associated with the latter two NDR types (northward and westward storm movement; Figs. 10b and 10c) are similar to those of CEMR and CEMSR (Figs. 7a and 7c), respectively, a preliminary study suggests that short-wave troughs may be responsible for the nondiurnal nature of NDR events.

The 500-hPa composites of geopotential height and specific humidity discussed above show that regime type is associated with the location of synoptic-scale features like the monsoon boundary, horizontal ridge axis of the subtropical high, and the meridional moisture axis. These findings support and expand upon the previous literature showing that midlevel synoptic-scale flow and moisture fields are important for distinguishing breaks from bursts. The similarity of 500-hPa flow between the six regimes and monsoon modes found by Cavazos et al. (2002) indicates that the six regimes exemplify intraseasonal variability typical of the NAM.
Section 4 further validates the essential features of the composite $500-\mathrm{hPa}$ maps by constructing composite 1200 UTC Phoenix soundings and relating the mean vertical structure of the local environment to each regime.

The six regimes characterize the temporal and spatial variations in storm development observed by a detailed, manual analysis of radar reflectivity mosaic data and show that similar storm development patterns occurred during both the 1997 and 1999 NAMs. Given the time-intensive nature of our approach and the relatively small size of our dataset, can an automated, more quantitative approach be developed to expand the dataset to other years? Section $3 \mathrm{~g}$ explores the use of hourly regional percent coverage time series for discerning the six regimes.

\section{g. Quantification of regional and temporal characteristics}

To quantify regional and temporal characteristics of storm development, the hourly percent coverage of composite radar reflectivity mosaics $25 \mathrm{db} Z$ and higher is computed over the eastern mountains (EM), central mountains (CM), and Sonoran Desert (SD; Fig. 1). To discern differences in percent coverage associated with the six regimes, a new parameter, daily percent coverage, defined as the average percent coverage over each region during a 24-h period, is computed. A comparison of daily percent coverage distributions over EM, CM, and SD associated with each regime indicates that this parameter may be useful as a tool for separating events 


\section{(a) NDR East-moving}

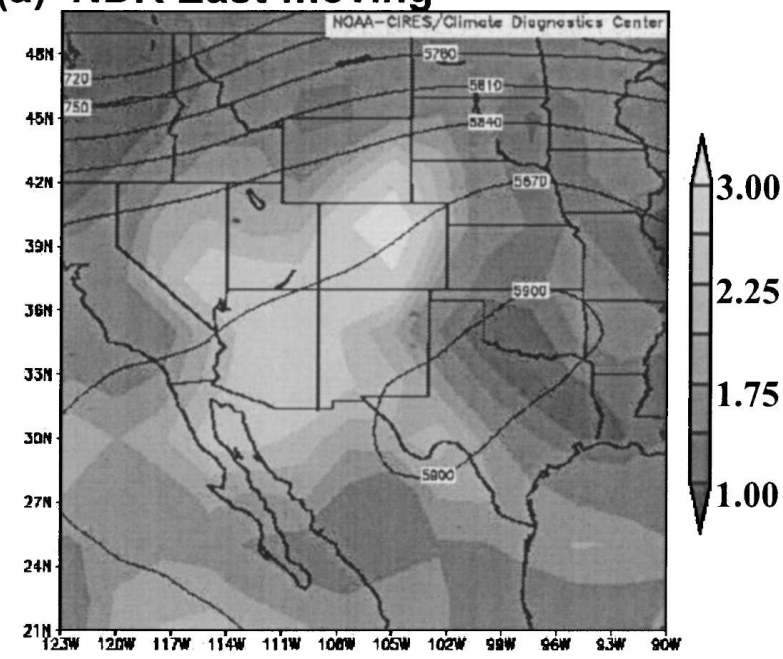

(b) NDR North-moving

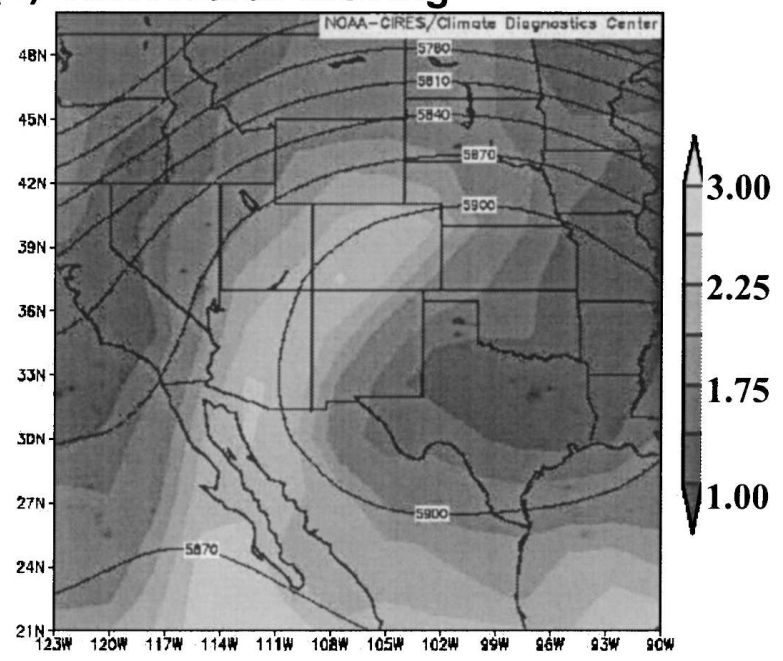

(c) NDR West-moving

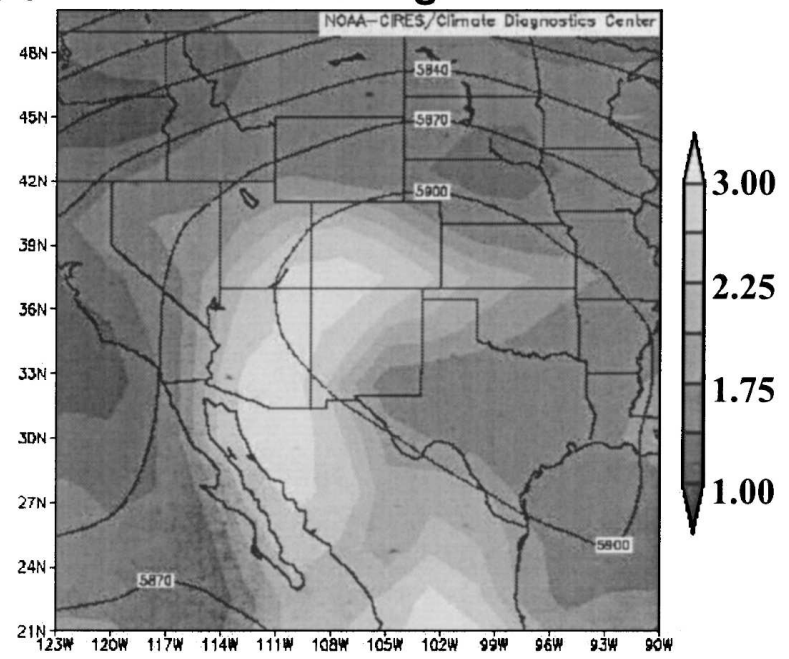

FIG. 10. Same as in Fig. 3, but for NDR, where storm movement is (a) eastward $(N=4)$, (b) northward $(N=8)$, and (c) westward $(N=8)$ into the following categories: DR, EMR, CEMR, and events with storm development over all three regions (CEMSIR, CEMSR, and NDR).

This tool employs fuzzy logic membership functions that assign a weight (ranging from 0.0 to 1.0 ) to daily percent coverage values over each region (Fig. 11). These membership functions are derived from daily percent coverage distributions over EM, CM, and SD. For each regime, three membership functions (EM, $\mathrm{CM}$, and SD) are computed and then averaged. These regime averages are then ranked and the event is classified based on the highest-ranked regime. This fuzzylogic scheme classifies all EMR and CEMR events correctly and all but two (83\%) of the DR events correctly (the two incorrect classifications include a tie with EMR and one incorrectly classified as EMR because of ground clutter over SD). Thus, daily percent coverage is a good parameter for discerning substantial regional differences in storm coverage over a 24-h period.

Manual analysis of CEMSIR, CEMSR, and NDR revealed that NDR is different from CEMSIR and CEMSR in that storm development is less closely tied to the diurnal cycle. An examination of time series of percent coverage reveals that during NDR the percent coverage over SD is oftentimes much higher from 1200 to 1700 UTC than that observed during CEMSIR and CEMSR. To quantify these morning differences in percent coverage a second parameter, morning percent coverage, defined as the average percent coverage over SD during 1200-1700 UTC, is computed. The distribution of morning percent coverage values over SD indicates that values $1 \%$ and higher discriminate best NDR from CEMSIR and CEMSR (not shown). This threshold classifies correctly 21 of the 30 (70\%) NDR events and classifies correctly 29 of the 39 (74\%) combined CEMSIR and CEMSR events.

This exploration of the use of time series of regional percent coverage for discerning the six regimes reveals limitations of employing this approach to classify the most common events: CEMSR and NDR. Because of the similarity of daily percent coverage over EM, CM, and SD among these events, daily percent coverage was not useful for separating these events. More useful was the morning percent coverage parameter, which correctly classified at least $70 \%$ of these events. The other $30 \%$ of these events remain improperly classified because of the inability of this quantitative method to measure characteristics of storm development like orientation and movement of storms relative to terrain features. Thus, our results suggest that applying such classification schemes to expand the dataset requires both automated and manual approaches. 

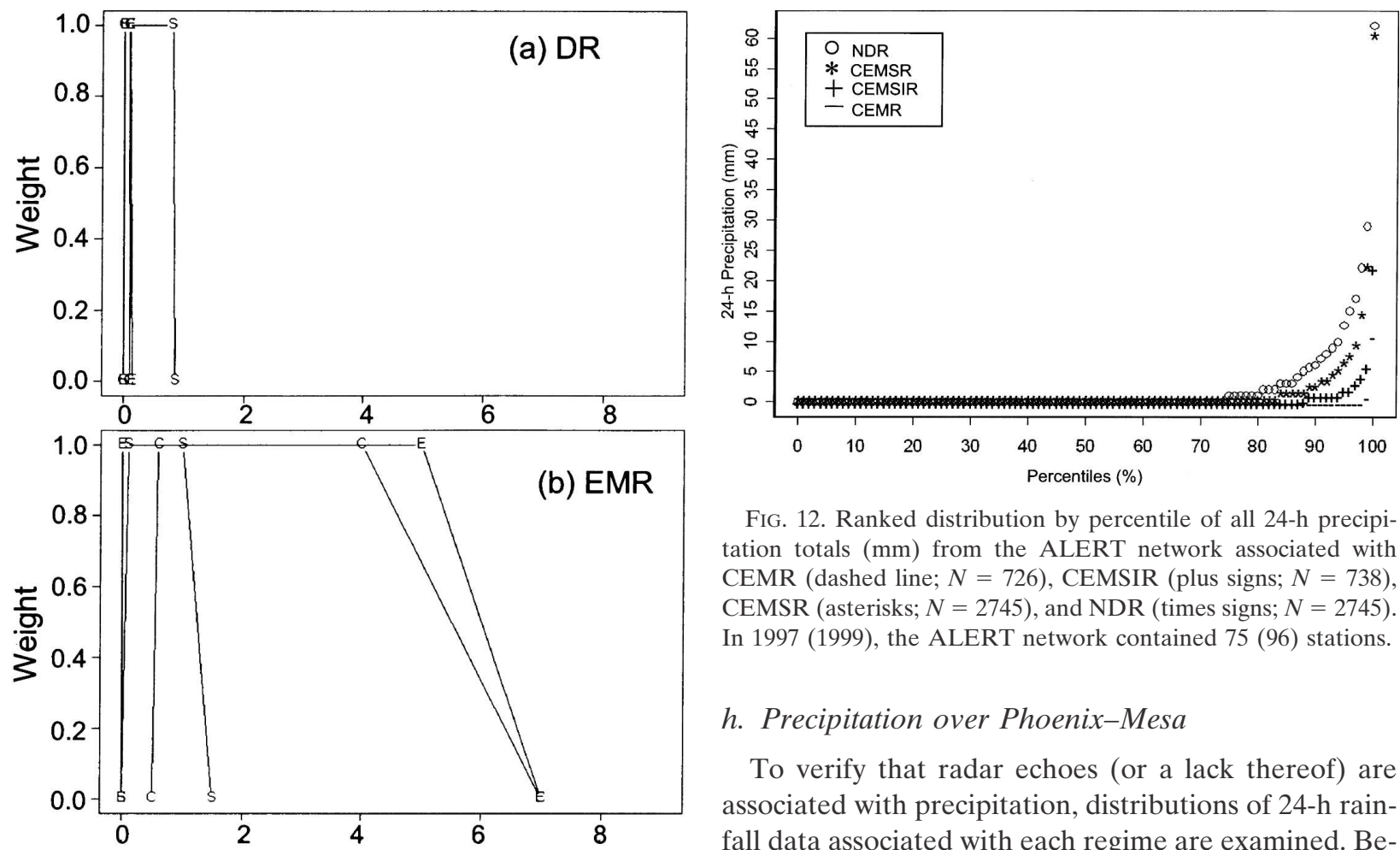

FIG. 12. Ranked distribution by percentile of all 24-h precipitation totals $(\mathrm{mm})$ from the ALERT network associated with CEMR (dashed line; $N=726$ ), CEMSIR (plus signs; $N=738$ ), CEMSR (asterisks; $N=2745$ ), and NDR (times signs; $N=2745$ ). In 1997 (1999), the ALERT network contained 75 (96) stations.

\section{h. Precipitation over Phoenix-Mesa}

To verify that radar echoes (or a lack thereof) are associated with precipitation, distributions of 24-h rainfall data associated with each regime are examined. Because of the societal impacts of summer storms on Phoenix-Mesa, we chose observations of 24-h rainfall obtained from the Automated Local Evaluation in Real Time (ALERT) rain-gauge network (information online at http://www.fcd.maricopa.gov/Services/ALERT; Fig. 1). This region was also chosen for its high density of rain gauges (75 in 1997 and 96 in 1999). The associated domain extends latitudinally $32.83^{\circ}-33.76^{\circ} \mathrm{N}$, and longitudinally $111.39^{\circ}-113.12^{\circ} \mathrm{W}$ (Fig. 1 ).

Validation begins by ranking ALERT observations from lowest to highest 24-h precipitation amounts for all days within each regime. Because of a relatively small number of nonzero values found in each regime's ranked rainfall data, differences in measurable rainfall amounts are made more discernible by computing percentiles of 24-h rainfall amounts associated with each regime (Fig. 12). As expected, no measurable precipitation is reported within the ALERT network during DR or EMR (not shown). During CEMR, $2 \%$ of the precipitation values at all stations are nonzero, whereas $12 \%, 16 \%$, and $25 \%$ of precipitation values are nonzero (0.01 in. or higher) during CEMSIR, CEMSR, and NDR, respectively (Fig. 12). The increase in percent of precipitation observations during CEMSIR, CEMSR, and NDR corresponds with higher rainfall values within these events (Fig. 12). The nonparametric Wilcoxon-Mann-Whitney rank-sum test is employed to test the statistical significance of observed differences in location (overall magnitude) of these precipitation CEMR, and (d) other (CEMSIR + CEMSR + NDR), where E, $\mathrm{C}$, and $\mathrm{S}$ represent percent coverage over the eastern mountains, central mountains, and Sonoran Desert, respectively. 
distributions (Wilks 1995, 138-142). Results of this test indicate that the distribution of precipitation over Phoenix-Mesa during CEMR is different from that during CEMSIR, CEMSR, and DR at a statistically significant level ( $p$ value $\leq 0.003$ ). The relative lack of 24-h accumulated precipitation over Phoenix-Mesa and the surrounding area during CEMR corroborates the absence of relative frequencies of reflectivity during DR, EMR, and CEMR, compared with CEMSIR, CEMSR, and NDR. Although CEMSIR, CEMSR, and NDR produce precipitation over Phoenix-Mesa, both CEMSIR and CEMSR have rainfall distributions considered different from NDR at statistically significant levels ( $p$ value $=0.01$ and 0.10 , respectively $)$.

\section{Characteristics of composite 1200 UTC Phoenix soundings}

Phoenix soundings collected during the 1997 and 1999 NAMs depict the composite vertical structure of the local environment corresponding to each regime. The 1997 dataset marks the first nearly complete record of sounding data recorded at Phoenix during the NAM, thanks to the Southwest Area Monsoon Project. These soundings were launched by staff at the Luke Air Force (LAF) Base Weather Detachment and measured by loran-tracked Väisälä soundings at 10-s intervals. Thereafter, the Salt River Project, a power company in Phoenix, began funding 1200 UTC sounding releases from the Phoenix National Weather Service Forecast Office (NWSFO), located approximately $40 \mathrm{~km}$ southeast of LAF (Fig. 1). The 1999 sounding data were collected at the Phoenix NWSFO at 5-s intervals using GPS15-tracked Väisälä soundings. Because of the forecast utility of these data (Dempsey et al. 1998), soundings at the Phoenix NWSFO were released from midJune through mid-September at primarily 1200 UTC and transmitted over the Global Telecommunications System. Morning (1200 UTC) sounding data are used to study the composite prestorm environment of each regime. Prior to compositing, quality control is performed by excluding soundings that are incomplete [e.g., missing wind profiles or deep layers of thermodynamic data; Schwartz and Doswell (1991)] or lacking corresponding radar data. Following this procedure, 79 soundings are available for analysis. After applying a five-point filter to the data, a composite sounding is created for each regime by computing the average temperature, dewpoint, and wind vector every $25 \mathrm{hPa}$ between 950 and $200 \mathrm{hPa}$. For NDR events, composite sounding characteristics are computed for each storm movement category: eastward, northward, and westward moving. This section proceeds with a discussion of similarities and differences in tropospheric moisture and instability among the six regimes.

One of the most striking differences between the DR and EMR composite soundings is the relative amount of tropospheric moisture (Fig. 13). Hence, the mean precipitable water (PW) values, defined as the total atmospheric water vapor contained in a vertical column of unit cross-sectional area extending between any two specified levels (here, the surface and $400 \mathrm{hPa}$ ), increases from $14 \mathrm{~mm}$ for DR to $26 \mathrm{~mm}$ for EMR. In addition, EMR's profile is cooler within the 775-570$\mathrm{hPa}$ layer than DR's profile and has steeper lapse rates between 850 and 600 hPa (Fig. 13). Thus, EMR's lowmidlevel conditions depict an environment that is moister and less stable compared with DR. The low PW values of DR correspond to a wind profile having unidirectional westerlies with height, whereas the higher PW values of EMR are associated with a wind profile with nearly unidirectional southwesterlies with height (Fig. 13).

During CEMR, CEMSIR, and CEMSR, the mean PW values are 34, 41, and $37 \mathrm{~mm}$, respectively (Fig. 13). Although PW values for CEMR, CEMSIR, and CEMSR are higher than those for DR and EMR, higher values of PW are not always associated with higher regional storm coverage (cf. Figs. 13 and 14). A comparison of CEMR, CEMSIR, and CEMSR profiles at $500 \mathrm{hPa}$ and below reveals light westerlies, southerlies, and southeasterlies, respectively (Fig. 14). These differences in wind direction at and below $500 \mathrm{hPa}$ correspond to differences in the location of the monsoon boundary. Above $500 \mathrm{hPa}$ the wind profiles are similar: southerlies with speeds that increase with height (Fig. 14). The CEMSR wind profile is similar to the average Tucson 1200 UTC wind profile associated with convective storm days in Phoenix (Fig. 9 of Wallace et al. 1999).

During NDR, the mean PW values are 35, 37, and 39 $\mathrm{mm}$ for north-, east-, and west-moving events, respectively (37 mm for all events combined; Fig. 15). Mean wind profiles associated with NDR events (eastward, northward, and westward moving) are similar to those of CEMR, CEMSIR, and CEMSR at and below 500 $\mathrm{hPa}$ : southwesterlies (slightly less westerly than in the CEMR profile), southerlies, and southeasterlies, respectively (cf. Figs. 14 and 15). The most notable difference is that NDR profiles contain stronger magnitudes, particularly within the $850-500-\mathrm{hPa}$ layer (cf. Figs. 14 and 15). Regardless of the similarities between wind profiles of NDR events and CEMR, CEMSIR, and CEMSR, only during NDR events is storm movement related directly to the steering-level flow.

The distinctive quality of $\mathrm{PW}$ is illustrated by the 


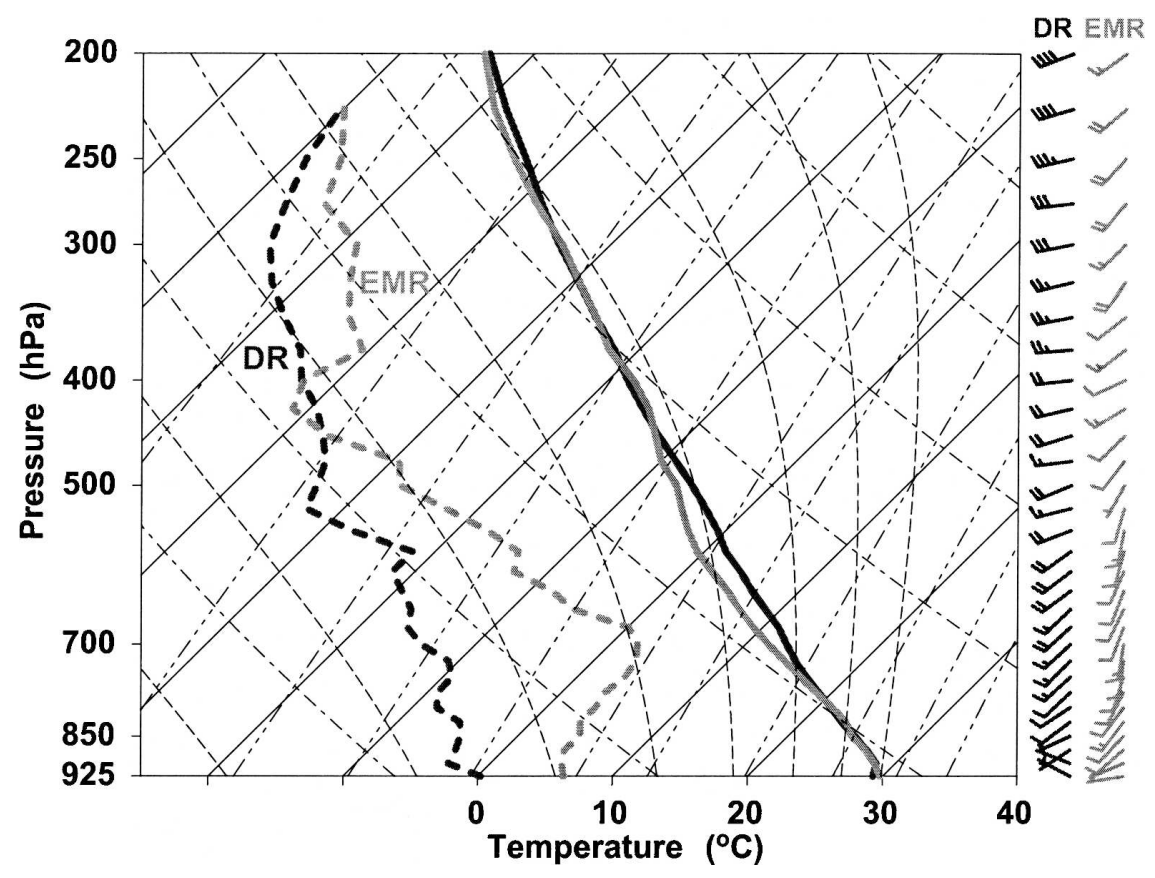

FIG. 13. Composite 1200 UTC soundings at Phoenix for DR (black lines; $N=12$ ) and EMR (gray lines; $N=7$ ), where $N$ denotes the number of soundings, with temperature (solid lines) and dewpoint temperature (dashed lines) in ${ }^{\circ} \mathrm{C}$. Winds are $5 \mathrm{~m} \mathrm{~s}^{-1}$ for full barbs and $2.5 \mathrm{~m} \mathrm{~s}^{-1}$ for half barbs.

drastically different distributions found between DR, EMR, and regimes with higher regional storm coverage (CEMR, CEMSIR, CEMSR, and NDR; Fig. 16). Applying a two-sided Wilcoxon-Mann-Whitney rank-sum test (Wilks 1995, 138-140) confirms that differences in the aforementioned distributions are statistically significant: all have $p$ values of 0.04 or lower. For regimes with relatively high storm coverage, differences in $\mathrm{PW}$ distributions are statistically significant only when comparing CEMR and CEMSIR $(p$ value $=0.07)$ and CEMSIR and NDR ( $p$ value $=0.08)$.

From a synoptic-scale perspective, the higher PW values of EMR, compared with DR, result from a significant change in the synoptic-scale pattern (Figs. 3a and $3 \mathrm{~b}$ ), whereas the higher PW values of CEMR, CEMSIR, CEMSR, and NDR, compared with EMR, result from shifts in the location of the monsoon boundary (cf. Figs. 3b, 7, and 10). This result is confirmed further by the 8-mm increase in mean PW from EMR to CEMR (cf. Figs. 13 and 14), which is comparable to perturbations of PW across the monsoon boundary $[\sim 6$ mm; Adang and Gall (1989)]. The location of the monsoon boundary, relative to Phoenix, is also indicated by regime wind profiles, where unidirectional southerlies or southeasterlies dominate the wind profile when the monsoon boundary is located west of Phoenix [cf. Figs. 13, 14, and 15; Adang and Gall (1989)]. The tropo- spheric moistening and concomitant wind shift from relatively dry (DR, EMR) to relatively wet (CEMR, CEMSIR, CEMSR, and NDR) regimes corresponds with changes in average Tucson 1200 UTC sounding characteristics from dry days to monsoon days (Fig. 4 of Wallace et al. 1999) and changes in mixing ratio and wind in time-height sections at Tucson from premonsoon to postmonsoon conditions (Fig. 4 of Adang and Gall 1989).

\section{Summary}

Historically, intraseasonal storm development over Arizona is depicted by wet and dry periods related, at least in part, by differences in midlevel synoptic-scale flow (Carleton 1986; Watson et al. 1994b; Mullen et al. 1998; Cavazos et al. 2002). This study shows that intraseasonal variability over Arizona during the 1997 and 1999 NAMs is more complicated than this binary stratification. Rather, six reflectivity patterns, or regimes, occur during these NAMs. During DR, rainfall is absent, whereas during EMR and CEMR storm cell development dominates over the eastern mountains and central mountains, respectively. The remaining three regimes differ from those above in that storms occur not only over the eastern and central mountains, but occur also over the Sonoran Desert. The first is 


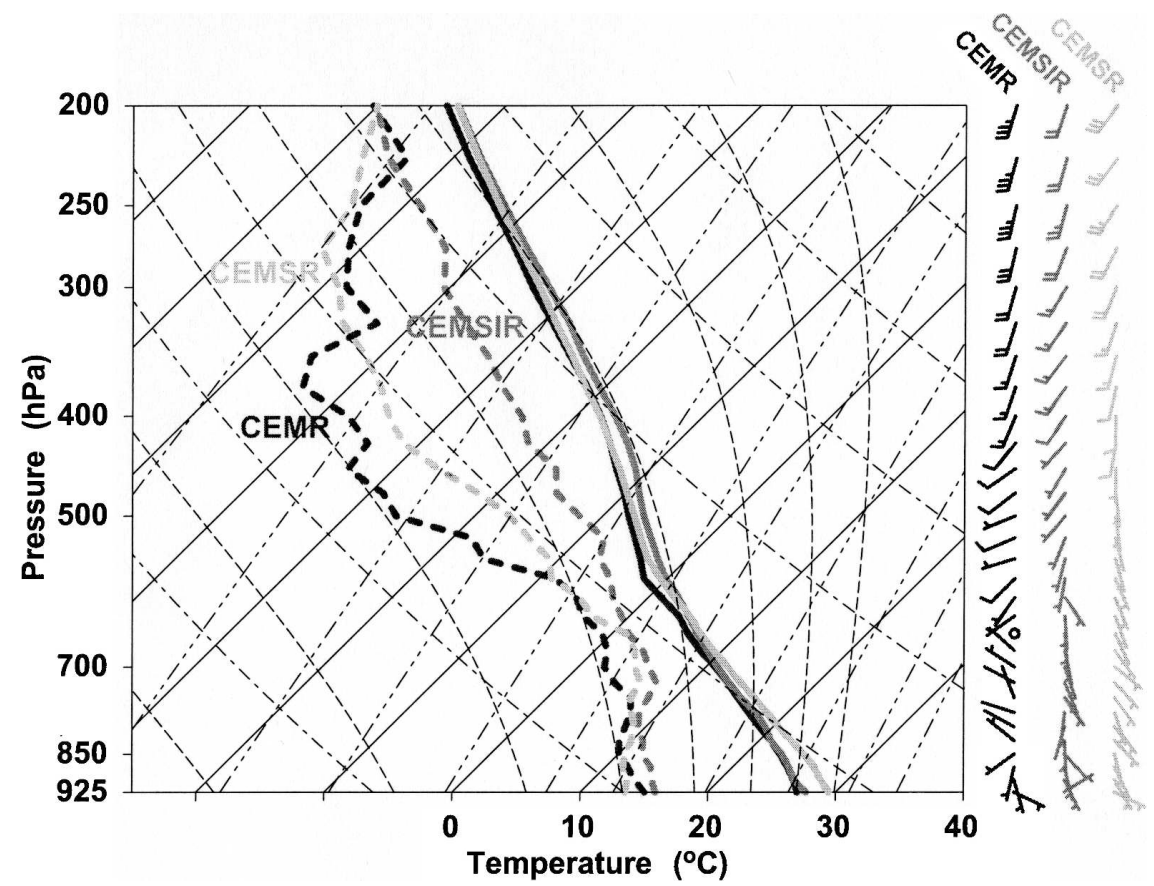

FIG. 14. Composite 1200 UTC soundings at Phoenix for CEMR (black lines; $N=7$ ), CEMSIR (medium gray lines; $N=9$ ), and CEMSR (light gray lines; $N=24$ ). Winds are 5 $\mathrm{m} \mathrm{s}^{-1}$ for full barbs and $2.5 \mathrm{~m} \mathrm{~s}^{-1}$ for half barbs.

CEMSIR, where early afternoon through evening storm development over the higher elevations of the San Francisco Mountains, Mogollon Rim, White Mountains, and southeast highlands is accompanied by iso- lated storm development over the Sonoran Desert. The second is CEMSR, where storm development is similar to Arizona's precipitation climatology: storms develop first over the peaks of the Mogollon Rim and southeast

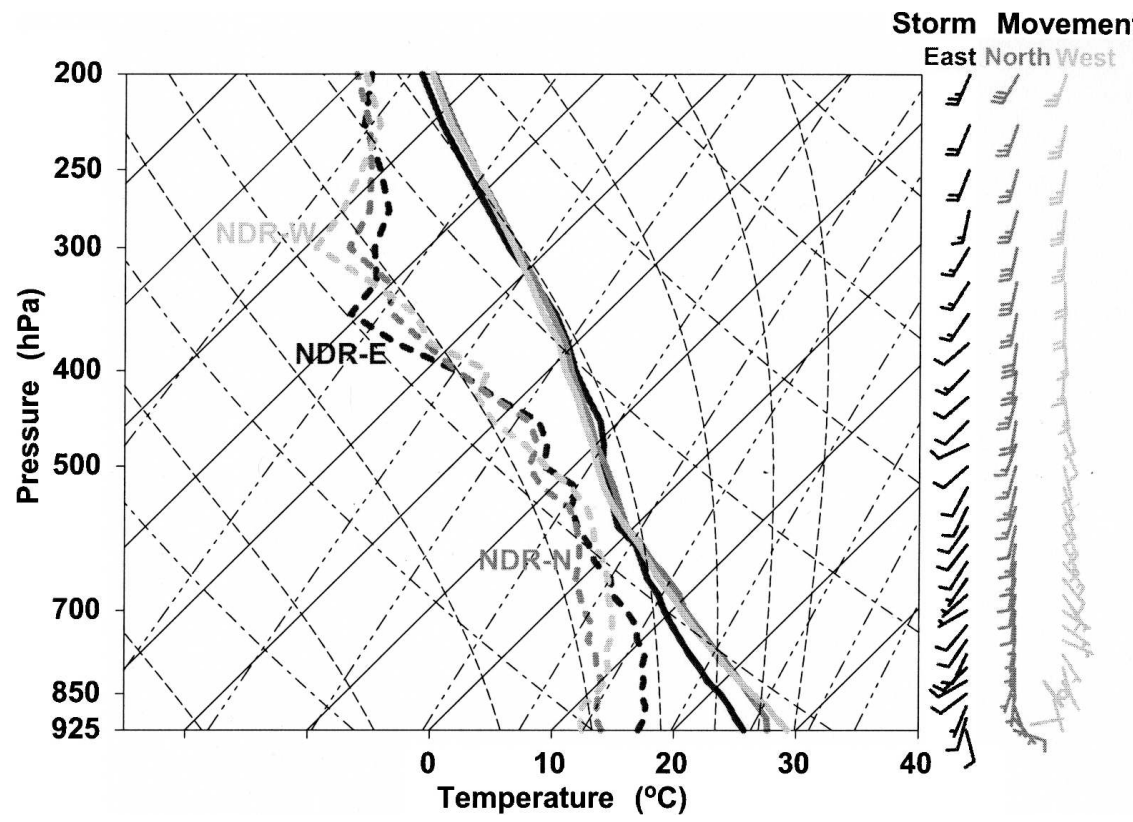

FIG. 15. Composite 1200 UTC soundings at Phoenix for NDR, where storms move eastward (black lines; $N=4$ ), northward (gray lines; $N=8$ ), or westward (light gray lines; $N=8$ ). Winds are $5 \mathrm{~m} \mathrm{~s}^{-1}$ for full barbs and $2.5 \mathrm{~m} \mathrm{~s}^{-1}$ for half barbs. 


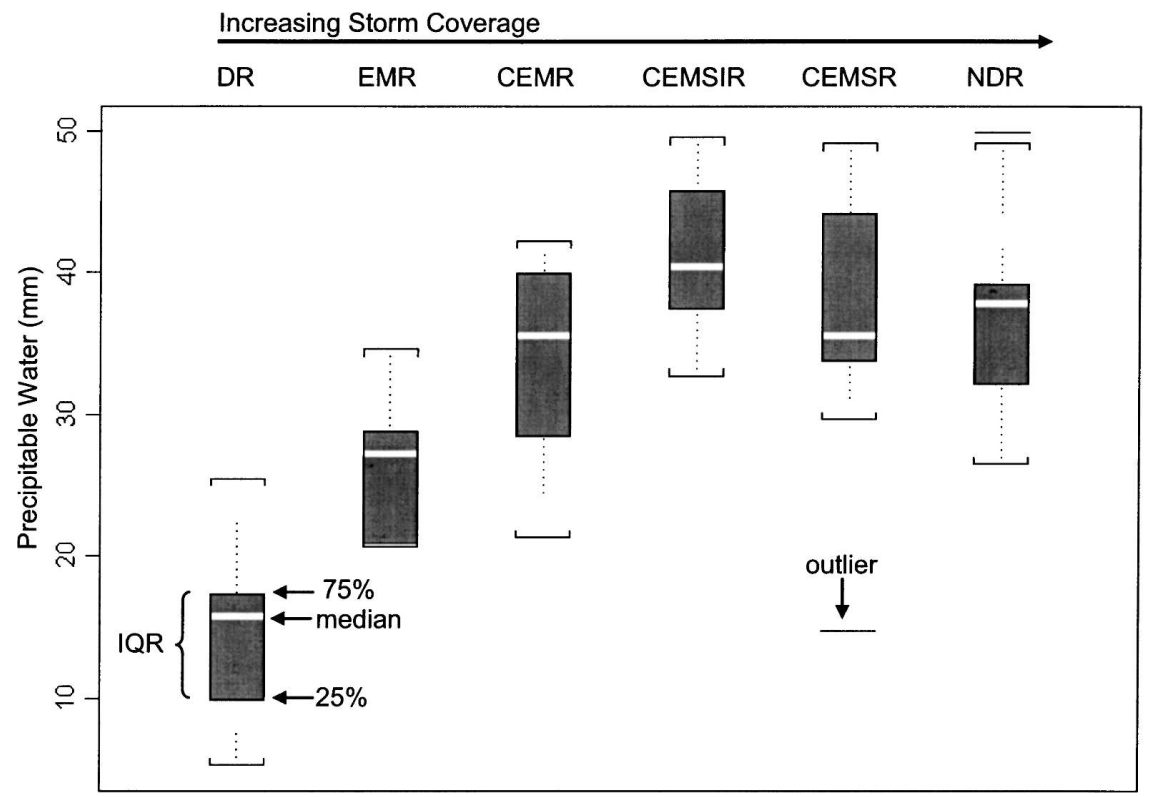

FIG. 16. Box and whisker plot of PW (surface- $400 \mathrm{hPa}$; mm), calculated from the 1200 UTC soundings at Phoenix. Filled boxes show the data distribution within the 25 th and 75 th percentiles, where the median is denoted by a thick white line. Outermost braces indicate values within $1.5 \times$ interquartile range $(\mathrm{IQR}$, defined as the difference between the 75 th and 25 th percentiles), whereas isolated horizontal lines indicate outliers.

highlands, later move toward lower elevations, and culminate within the Sonoran Desert. The third is NDR, where storm development is tied less closely to the diurnal cycle. Furthermore, during NDR, storm development tends to be organized as a convective line or mesoscale convective system, rather than as isolated cells. Based on these differences in regional storm coverage, we conclude that intraseasonal variability within breaks includes DR and EMR, whereas intraseasonal variability within bursts includes CEMR, CEMSIR, CEMSR, and NDR.

Because of the diversity of regimes, previously constructed synoptic-scale composites of breaks and bursts are insufficient to determine the environmental conditions characteristic of each regime. Examining composite 1200 UTC 500-hPa maps and Phoenix soundings associated with each regime shows that the synopticscale flow is related to the occurrence of the six regimes. Furthermore, in all cases, analyses of daily 1200 UTC Phoenix soundings show that PW is useful for discerning regime type. Although these analyses were derived from only two NAM seasons (1997 and 1999), the similarity of 500-hPa composites to modes found by Cavazos et al. (2002) suggests that the regimes are representative of at least a subset of intraseasonal variability over Arizona.

Based on these results, the following conceptual model is proposed. The occurrence of the six regimes is regulated by the $500-\mathrm{hPa}$ flow, where variations in this flow depend on the evolution of the North Pacific trough and subtropical high. In turn, the position of these circulations regulates the location of the meridional moisture axis. The location of the meridional moisture axis is important to regional summer storm development because it indicates regions of deep tropospheric moisture associated with the monsoon boundary (Adang and Gall 1989). Consequently, 500hPa synoptic-scale flow that prohibits the advection of moist air into Arizona, such as a subtropical ridge axis at $30^{\circ} \mathrm{N}$, is strongly indicative of DR. However, on most days, the subtropical ridge axis is shifted northward, so that the meridional extent of the North Pacific trough and subtropical high determine the location of the monsoon boundary. Accordingly, when the monsoon boundary is located over eastern Arizona, the diurnal heating cycle supports storm development similar to EMR. Westward shifts in the monsoon boundary result in deep moisture over larger regions of Arizona and more extensive storm development (e.g., CEMSR and NDR). Because the location of the meridional moisture axis corresponds well with PW values at Phoenix, the 1200 UTC PW values at Phoenix may be used to discern DR from EMR, and the break-type regimes (DR and EMR) from the burst-type regimes (CEMR, CEMSIR, CEMSR, and NDR). However, once the monsoon boundary and meridional moisture axis are 


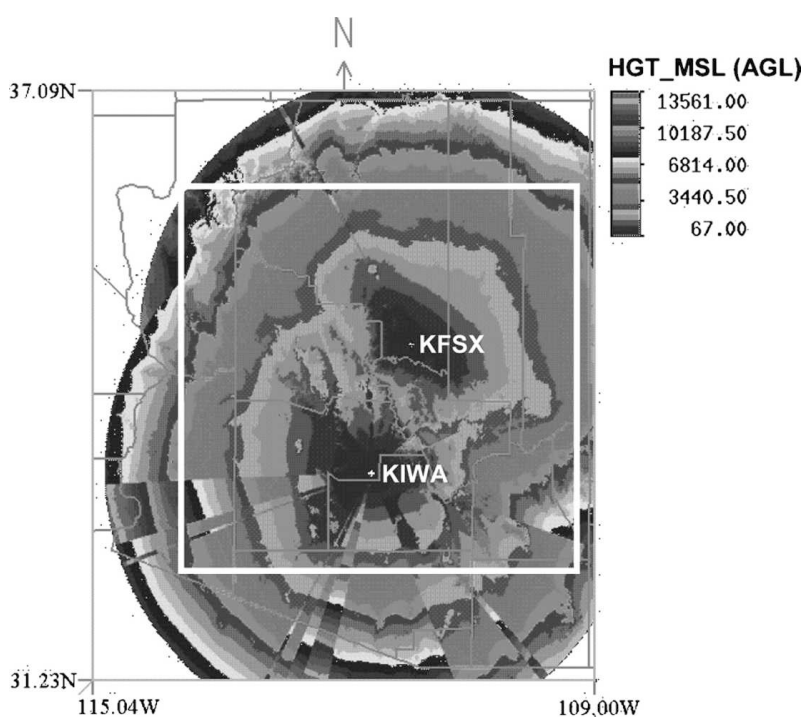

FIG. A1. Height of the hybrid scan, or lowest elevation above 50 m (164 ft), where data are collected for KIWA and KFSX WSR88Ds (m AGL; courtesy of J. Zhang). The thick white box denotes this study's domain.

located west of Phoenix, values of PW are less useful for discerning CEMSIR, CEMSR, and NDR.

Acknowledgments. We thank Drs. Frederick Carr, Michael Richman, Alan Shapiro, David Stensrud, and May Yuan for their thorough reviews of the dissertation that led to this manuscript. Thanks also to Dr. Jian Zhang who provided the adaptive Barnes interpolation and mosaic code and to John Hart who provided his NSHARP code. We thank the anonymous reviewers and Steve Mullen for their comments and suggestions. This work was funded by the Salt River Project and NOAA/OAR/NSSL under NOAA-OU Cooperative Agreement NA17RJ1227.

\section{APPENDIX}

\section{Quality Control, Adaptive Barnes Interpolation, and the Mosaic Technique}

Quality control techniques are applied to minimize the echo from nonmeteorological sources, including ground clutter and anomalous propagation. In this quality control process, a bin of radar reflectivity is considered ground clutter if its height is below the height of the hybrid reflectivity level (Gourley et al. 2001). The hybrid reflectivity level is defined as the height where one of the four lowest radar tilts is at least $50 \mathrm{~m}(164 \mathrm{ft})$ above ground level (see Fig. A1 for heights of the KIWA and KFSX hybrid scan). As illustrated in Fig. A1, the height of the hybrid reflectivity level increases most quickly with increasing range from the radar in regions where terrain blocks the radar beam. Thus, within radials of rapid increases in the height of the radar beam, the lowest elevation angle of KIWA or KFSX may overshoot the storm top.

A radar reflectivity observation is considered anomalous propagation, or surface ducting of the radar beam, if it is nearly stationary (corresponding velocity magnitude is $2.5 \mathrm{~m} \mathrm{~s}^{-1}$ or less) and the magnitude of the reflectivity value above the observation is comparatively small (Gourley et al. 2001). Specifically, significant decreases in reflectivity with height are considered nonmeteorological if the reflectivity value within a bin at the tilt just above the hybrid tilt height is at least $90 \%$ lower than the reflectivity value within a corresponding bin at the hybrid tilt height (Gourley et al. 2001). Radar reflectivity data identified as ground clutter or anomalous propagation are removed from the dataset.

Following data quality control, the radar-coordinate radar reflectivity volumes from each radar are interpolated onto a three-dimensional Cartesian grid by performing an adaptive Barnes interpolation scheme (e.g., Askelson et al. 2000; Trapp and Doswell 2000). The details of the employed scheme are described below. The Cartesian grid has a cylindrical equidistant latitude-longitude reference frame, such that only distances along standard parallels and meridians are true to scale. The Cartesian grid is $440 \mathrm{~km} \times 440 \mathrm{~km}$ in the horizontal dimension (Fig. 1), with 1-km grid spacing in the horizontal and 21 stretched levels in the vertical (surface-12 km), such that height intervals increase hyperbolic tangentially with increasing height.

The raw reflectivity factor $f$ is interpolated from radar coordinates, $f_{i}(r, \theta, \phi)$, to Cartesian coordinates, $f_{g}(x, y, z)$, by performing an adaptive Barnes interpolation scheme (e.g., Askelson et al. 2000; Trapp and Doswell 2000):

$$
f_{g}(x, y, z)=\frac{\sum_{i=1}^{N} w_{i} f_{i}(r, \theta, \phi)}{\sum_{i=1}^{N} w_{i}},
$$

where the weighting factor $w_{i}$ defined as

$$
w_{i}=\exp \left[-\frac{\left(r_{g}-r_{i}\right)^{2}}{\kappa_{r}}-\frac{\left(\theta_{g}-\theta_{i}\right)^{2}}{\kappa_{\theta}}-\frac{\left.\phi_{g}-\phi_{i}\right)^{2}}{\kappa_{\phi}}\right],
$$

where $r, \theta$, and $\phi$ represent the polar coordinates of distance, azimuth, and elevation, respectively; $x, y, z$ represent the Cartesian coordinates of horizontal distance and height; the subscript $i$ represents a bin of raw reflectivity data in polar coordinates; the subscript $g$ 
represents a grid point of interpolated reflectivity data in Cartesian coordinates; $N$ is the number of radar bins influencing the interpolated grid value; and $\kappa_{r}, \kappa_{\theta}$, and $\kappa_{\phi}$ are the dimensional filtering parameters. These dimensional filtering parameters are a function of $r$ only, and are defined in appendix A of Heinselman (2004).

The influence region of $f_{g}(x, y, z)$ is volumetric and defined in polar coordinates, such that radar bins located within $5-\mathrm{km}$ radial distance, $2^{\circ}$ azimuth, and within the two closest elevation scans above and below the grid point contribute toward that point's weighted reflectivity value. Because the resolution of the radar reflectivity data decreases in the azimuthal and vertical directions with increasing range from the radar, the region of influence applied to grid points located far from the radar is larger than the region of influence applied to grid points located near the radar. In both situations, the region of influence includes the same number of data points. Since azimuthal- and elevation-length scales increase with increasing range, filtering $\left[\kappa_{\theta}(r)\right.$ and $\left.\kappa_{\phi}(r)\right]$ is range-dependent in these dimensions (Heinselman 2004).

Once each volume scan of reflectivity from the KIWA and KFSX radars is interpolated onto the Cartesian grid, a three-dimensional reflectivity mosaic is created by combining radar data at each Cartesian level $z$. Use of two radars minimizes radar data limitations such as beam blockage and decreasing resolution with increasing range, and composes a more complete depiction of storm structure and precipitation than either radar alone could provide. At each level $z$, interpolated reflectivity values, $f_{g}(x, y, z)$, are mosaicked to each grid point, $f_{m}(x, y, z)$, in the domain using an inverse distance-weighted average (Zhang et al. 2005):

$$
f_{m}(x, y, z)=\frac{\sum_{n=1}^{\text {nradars }} w_{n}(x, y, z) f_{g}^{n}(x, y, z)}{\sum_{n=1}^{\text {nradars }} w_{n}(x, y, z)},
$$

where nradars is the number of radars that cover each grid point (nradars $=2), f_{g}^{n}(x, y, z)$ is the interpolated reflectivity value from the $n$th radar, and $f_{m}(x, y, z)$ is the mosaicked value at each grid point. The weight $w_{n}$ given to a radar observation is dependent on the distance between the radar and the observation [i.e., Cressman weight function; Zhang et al. (2005)]:

$$
w_{n}(x, y, z)=\frac{R_{\mathrm{inf}}^{2}-d_{n}^{2}(x, y, z)}{R_{\mathrm{inf}}^{2}+d_{n}^{2}(x, y, z)},
$$

where $R_{\text {inf }}$ is the farthest range at which a valid observation is attainable $\left(R_{\mathrm{inf}}=300 \mathrm{~km}\right)$ and $d_{n}(x, y, z)$ is the distance between a mosaic grid point and the $n$th radar. The final three-dimensional radar reflectivity mosaic is created every $10 \mathrm{~min}$. A composite reflectivity mosaic is also computed, which compresses the three-dimensional Cartesian grid into a two-dimensional field of maximum reflectivity value within each $1 \mathrm{~km} \times 1 \mathrm{~km} \times$ 12-km column.

\section{REFERENCES}

Adams, D. K., and A. C. Comrie, 1997: The North American monsoon. Bull. Amer. Meteor. Soc., 78, 2197-2213.

Adang, T. C., and R. L. Gall, 1989: Structure and dynamics of the Arizona monsoon boundary. Mon. Wea. Rev., 117, 14231438.

Anderson, B. T., H. Kanamaru, and J. O. Roads, 2004: The summertime atmospheric hydrologic cycle over the southwestern United States. J. Hydrometeor., 5, 679-692.

Askelson, M. A., J. P. Aubagnac, and J. M. Straka, 2000: An adaptation of the Barnes filter applied to the objective analysis of radar data. Mon. Wea. Rev., 128, 3050-3082.

Badan-Dangon, A., C. E. Dorman, M. A. Merrifield, and C. D. Winant, 1991: The lower atmosphere over the Gulf of California. J. Geophys. Res., 96, 877-896.

Balling, R. C., and S. A. Brazel, 1987: Diurnal variations in Arizona monsoon precipitation frequencies. Mon. Wea. Rev., 115, 342-346.

Barlow, M., S. Nigam, and E. H. Berbery, 1998: Evolution of the North American monsoon system. J. Climate, 11, 2238-2257.

Berbery, E. H., 2001: Mesoscale moisture analysis of the North American monsoon. J. Climate, 14, 121-137.

—_ and M. S. Fox-Rabinovitz, 2003: Multiscale diagnosis of the North American monsoon system using a variable resolution GCM. J. Climate, 16, 1929-1947.

Brenner, I. S., 1974: A surge of maritime tropical air-Gulf of California to the southwestern United States. Mon. Wea. Rev., 102, 375-389.

Bryson, R. A., and W. P. Lowry, 1955: Synoptic climatology of the Arizona summer precipitation singularity. Bull. Amer. Meteor. Soc., 36, 329-339.

Carleton, A. M., 1985: Synoptic and satellite aspects of the southwestern U.S. summer "monsoon." J. Climatol., 5, 389-402.

— 1986: Synoptic-dynamic character of 'bursts' and 'breaks' in the southwest U.S. summer precipitation singularity. J. Climatol., 6, 605-623.

Cavazos, T., A. C. Comrie, and D. M. Liverman, 2002: Intraseasonal variability associated with wet monsoons in southeast Arizona. J. Climate, 15, 2477-2490.

Dempsey, C. L., K. W. Howard, R. A. Maddox, and D. H. Phillips, 1998: Developing advanced weather technologies for the power industry. Bull. Amer. Meteor. Soc., 79, 1019-1035.

Douglas, M. W., 1995: The summertime low-level jet over the Gulf of California. Mon. Wea. Rev., 123, 2334-2347.

— California: Aspects of their climatology, mean structure, and evolution from radiosonde, NCEP reanalysis, and rainfall data. Wea. Forecasting, 18, 55-74.

- R. A. Maddox, and K. Howard, 1993: The Mexican monsoon. J. Climate, 6, 1665-1677.

Gourley, J. J., J. Zhang, R. A. Maddox, C. M. Calvert, and K. W. Howard, 2001: A real-time precipitation monitoring algorithm-Quantitative Precipitation Estimation and Segrega- 
tion Using Multiple Sensors (QPESUMS). Preprints, Symp. on Precipitation Extremes: Prediction, Impacts, and Responses, Albuquerque, NM, Amer. Meteor. Soc., 57-60.

Hales, J. E., 1972a: A study of radar echo distribution in Arizona during July and August. NOAA Tech. Memo. NWS WR-77, $21 \mathrm{pp}$.

_ 1972b: Surges of maritime tropical air northward over the Gulf of California. Mon. Wea. Rev., 100, 298-306.

__, 1974: Southwestern United States summer monsoon source-Gulf of Mexico or Pacific Ocean? J. Appl. Meteor., 13, 331-342.

—_, 1975: A severe southwest desert thunderstorm: 19 August 1973. Mon. Wea. Rev., 103, 344-351.

Heinselman, P. L., 2004: Intraseasonal variability of the North American monsoon over Arizona. Ph.D. dissertation, University of Oklahoma, $138 \mathrm{pp}$.

Higgins, R. W., Y. Yao, and X. L. Wang, 1997: Influence of the North American monsoon system on the U.S. summer precipitation regime. J. Climate, 10, 2600-2622.

_- W. Shi, and C. Hain, 2004: Relationships between Gulf of California moisture surges and precipitation in the southwestern United States. J. Climate, 17, 2983-2997.

Houghton, J. G., 1979: A model for orographic precipitation in the north-central Great Basin. Mon. Wea. Rev., 107, 14621475.

Johns, R. H., and C. A. Doswell III, 1992: Severe local storms forecasting. Wea. Forecasting, 7, 588-612.

Jurwitz, L. R., 1953: Arizona's two-season rainfall pattern. Weatherwise, 6, 96-99.

Kalnay, E., and Coauthors, 1996: The NCEP/NCAR 40-Year Reanalysis Project. Bull. Amer. Meteor. Soc., 77, 437-471.

Kanamitsu, M., and K. C. Mo, 2003: Dynamical effect of land surface processes on summer precipitation over the southwestern United States. J. Climate, 16, 496-509.

King, T. S., and R. C. Balling, 1994: Diurnal variations in Arizona monsoon lightning data. Mon. Wea. Rev., 122, 1659-1664.

MacKeen, P. L., and J. Zhang, 2000: Convective climatology for central Arizona during the 1999 monsoon. Postprints, Southwest Weather Symp., Tucson, AZ, NWS, COMET, and The University of Arizona, 64-67.

McCollum, D. M., R. A. Maddox, and K. W. Howard, 1995: Case study of a severe mesoscale convective system in central Arizona. Wea. Forecasting, 10, 643-668.

Mohr, M., 2004: Problems with the mean sea level pressure field over the western United States. Mon. Wea. Rev., 132, 19521965.

Mullen, S. L., J. T. Schmitz, and R. O. Renno, 1998: Intraseasonal variability of the summer monsoon over southeast Arizona Mon. Wea. Rev., 126, 3016-3035.

Rasmusson, E. M., 1967: Atmospheric water vapor transport and the water balance of North America: Part I. Characteristics of the water vapor flux field. Mon. Wea. Rev., 95, 403-426.

Rowson, D. R., and S. J. Colucci, 1992: Synoptic climatology of the thermal low-pressure systems over south-western North America. Int. J. Climatol., 12, 529-545.

Schmidli, R. J., 1986: Climate of Phoenix, Arizona. NOAA Tech. Memo. NWS WR-177, 114 pp.

Schmitz, J. T., and S. L. Mullen, 1996: Water vapor transport associated with the summertime North American monsoon as depicted by ECMWF analyses. J. Climate, 9, 1621-1634.

Schwartz, B. E., and C. A. Doswell III, 1991: North American rawinsonde observations: Problems, concerns, and a call to action. Bull. Amer. Meteor. Soc., 72, 1885-1896.

Sellers, W. D., and R. H. Hill, 1974: Arizona Climate 1931-1972. The University of Arizona Press, 616 pp.

Smith, W. P., and R. L. Gall, 1989: Tropical squall lines of the Arizona monsoon. Mon. Wea. Rev., 117, 1553-1569.

Stensrud, D. J., R. L. Gall, and M. K. Nordquist, 1997: Surges over the Gulf of California during the Mexican monsoon. Mon. Wea. Rev., 125, 417-437.

Tang, M., and E. R. Reiter, 1984: Plateau monsoons of the Northern Hemisphere: A comparison between North America and Tibet. Mon. Wea. Rev., 112, 617-637.

Trapp, R. J., and C. A. Doswell III, 2000: Radar data objective analysis. J. Atmos. Oceanic Technol., 17, 105-120.

Wallace, C. E., 1997: Convective storm environments in central Arizona during the summer monsoon. M.S. thesis, School of Meteorology, University of Oklahoma, $117 \mathrm{pp}$.

, R. A. Maddox, and K. W. Howard, 1999: Summertime convective storm environments in central Arizona: Local observations. Wea. Forecasting, 14, 994-1006.

Watson, A. I., R. L. Holle, and R. E. Lopez, 1994a: Cloud-toground lightning and upper-air patterns during bursts and breaks in the southwest monsoon. Mon. Wea. Rev., 122, $1726-1739$.

_ R. E. Lopez, and R. L. Holle, 1994b: Diurnal cloud-toground lightning patterns in Arizona during the Southwest monsoon. Mon. Wea. Rev., 122, 1716-1725.

Wilks, D. S., 1995: Statistical Methods in the Atmospheric Sciences. Academic Press, 464 pp.

Zhang, J., K. Howard, and J. J. Gourley, 2005: Constructing threedimensional multiple-radar reflectivity mosaics: Examples of convective storms and stratiform rain echoes. J. Atmos. Oceanic Technol., 22, 30-42. 